\title{
INTERGENERATIONAL EDUCATION MOBILITY AND THE LEVEL OF DEVELOPMENT: EVIDENCE FROM TURKEY
}

\author{
Abdurrahman B. Aydemir \\ Hakkı Yazıc1
}

Working Paper 1717

November 2017

This Working Paper is issued under the supervision of the ERF Directorate. Any opinions expressed here are those of the author(s) and not those of the Koç University-TÜSİAD Economic Research Forum. It is circulated for discussion and comment purposes and has not been subject to review by referees.

KOÇ UNIVERSITY-TÜSİAD ECONOMIC RESEARCH FORUM

Rumelifeneri Yolu 34450 Sariyer/Istanbul 


\title{
Intergenerational Education Mobility and the Level of Development: Evidence from Turkey ${ }^{1}$
}

\author{
Abdurrahman B. Aydemir and Hakki Yazici²
}

December 2015

This version: November 2017

\begin{abstract}
This paper provides two contributions to the study of intergenerational mobility. First, we render a thorough characterization of education mobility in Turkey at the national level, including a three-generation mobility analysis. We find that the education mobility is significantly lower in Turkey compared to developed economies. Second, by exploiting large regional variation in the level of economic development across Turkey, we find that intergenerational education persistence is lower for females who grow up in more developed regions. The evidence is mixed for males. Interestingly, the development level of place of residence during earlier stages of childhood has much stronger association with education mobility compared to development level of place of residence during later stages.
\end{abstract}

Keywords: intergenerational mobility, education, economic development, three generations

J.E.L. Classification: J6, I2, R0

\footnotetext{
${ }^{1}$ This research was supported by Tübitak research grant no. 112K502 and Sabanc1 University Internal Research Grant. We thank participants of the Intergenerational Transmission of Economic Status Workshop, Özyeğin University-World Bank Workshop on Poverty, Inequality and Intergenerational Mobility and Koc University Economics Seminar Series for their helpful comments. We especially thank Bhash Mazumder, Jan Stuhler, and Mikael Lindahl for their suggestions. We thank Istanbul School of Central Banking for their hospitality. Usual disclaimers apply.

${ }^{2}$ Corresponding author: Aydemir: Faculty of Arts and Social Sciences, Sabanci University, Orhanl1, Tuzla 34956, Istanbul, IZA, CREAM-UCL, aaydemir@sabanciuniv.edu, phone: 2164839344 , fax: 2164839250

Yazici: Faculty of Arts and Social Sciences, Sabanci University, Orhanl1, Tuzla 34956, Istanbul, hakkiyazici@sabanciuniv.edu, phone: 2164839331 ,fax: 2164839250
} 


\section{Introduction}

The degree to which socioeconomic performance persists from one generation to another is often interpreted as measuring a society's success in providing equality of opportunity to children from different family backgrounds. A high degree of intergenerational persistence suggests that family background plays an important role in children's later success in life while a low degree of persistence implies the opposite. In this paper, we analyze intergenerational mobility in education in a developing economy in the context of Turkey using information from a nationally representative survey that we conducted over November 2014 - February 2015 period. In addition to information on educational attainment of individuals and their parents, the survey includes unique and detailed information on people's place of residence at various stages of development during childhood. This information enables us to characterize how intergenerational mobility differs across people who grow up in regions with different levels of socioeconomic development.

The paper has two main parts. In the first part, we provide a thorough characterization of intergenerational education mobility in Turkey at the national level. We believe this is an important contribution to the literature on intergenerational mobility because even though there is an abundance of studies analyzing intergenerational mobility in developed countries, the evidence gathered for developing countries is still quite limited. We find that the correlation between father's (resp. mother's) and offspring's years of schooling is statistically significant and 0.564 (resp. 0.532). ${ }^{3}$ A comparison of these numbers with findings from Hertz et al. (2007), who provide comparable estimates of intergenerational correlations for a large set of countries, suggests that the level of education mobility is lower in Turkey than it is in the rest of the world, except for South American countries. We also find that intergenerational

\footnotetext{
${ }^{3}$ Following the existing literature, we measure intergenerational persistence in education using two closely related measures: the regression coefficient and the correlation coefficient. We discuss the measures and when it is more appropriate to use one measure rather than the other one in detail in Section 2.
} 
education mobility is significantly lower for females. Our survey also includes questions on the educational attainments of the respondents' children. We use this information to analyze the persistence of educational outcomes across three generations and find that grandparents' educational attainments have no effect on children's educational attainments when we control for the years of schooling of both parents.

In the second and main part of our paper, we characterize how intergenerational mobility varies with the level of economic development. To our knowledge, ours is the first study in the literature of how intergenerational education mobility varies with the development level of the region where people grow up. Turkey provides a unique case study for understanding the role of development in shaping intergenerational mobility for two reasons. First, Turkey is a large country where large disparities in the level of development exist across regions. In particular, there is substantial heterogeneity in income, educational attainment, school access and education quality. This large regional variation is what enables us to study how mobility changes with development. Second, Turkey has a relatively strong and unified state structure which imposes a fairly uniform institutional environment across the whole country. Thus, differences in institutional environments and data comparability issues, which complicate the study of the relationship between mobility and development across countries, are much less pressing in the current context. ${ }^{4}$

In order to investigate how intergenerational mobility changes with the level of development, we first construct a variable that measures the socioeconomic development level of the places people grew up in our sample. The Turkish Ministry of Development periodically measures various aspects of socioeconomic development throughout Turkey, and as a part of this process, the ministry has developed an index that summarizes the level of socioeconomic

\footnotetext{
${ }^{4}$ Moreover, Turkey is a fairly homogenous country in which inheritability of genetic factors that affect educational attainment presumably varies less across regions relative to cross-country variation in such traits. In this regard, regional variation in intergenerational mobility within Turkey is more likely to reflect the role of development in shaping mobility.
} 
development at the province level. Larger values of this index indicate more developed regions. In our analysis, we use the most recent index, Socio-economic Development Index for 2011 (SEGE-2011) as the proxy for the development level of each province. Our data includes separate information about the place of residence when individuals were between the ages of 0$6,7-12$, and 13-18, as well as their current place of residence. Since we are interested in people's educational attainment, the characteristics of the place where they grew up matter more than the characteristics of their current place of residence. For this reason, in our baseline analysis we assign an individual the development index value of the province he or she resided while growing up, and in particular, between the ages of 7 and 12 .

We modify the basic intergenerational regression equation by adding an interaction term between parents' years of schooling and the socioeconomic development variable we have constructed. We find that the coefficient of this interaction term is statistically significantly negative (regardless of whether we set fathers' or mothers' years of schooling as the parental education variable), indicating that intergenerational education mobility is higher in regions with higher levels of development. Interestingly, when we divide our sample into male and female subsamples and estimate the modified intergenerational regression equation separately for each subsample, we find that the coefficient of the interaction term is statistically significant only for females.

We repeat our estimations by assigning development index values according to the place of residence during the ages of $0-6,13-18$, and current place of residence as well. We find that the positive association between the development level of place of residence and intergenerational mobility is significantly stronger when we define place of residence as the place of residence during the ages of 0-6 and 7-12 rather than the place of residence during the ages of 13-18 or current place of residence. This is in line with the recent empirical findings on 
the importance of early childhood investments on adult outcomes. ${ }^{5}$ Moreover, when we restrict our sample to those whose current place of residence is different from place of residence during the ages of 0-6 and 7-12, the association between the development level of current place of residence and intergenerational mobility becomes insignificant. This finding implies that empirical work that aims to evaluate the effect of development on mobility using information on current residence is likely to underestimate the effect of development, and as such, it underlines the value of using information on people's place of residence while growing up.

We also conduct a nonparametric analysis of the relationship between development and intergenerational mobility. To do so, we partition the provinces individuals resided in Turkey while growing up into 15 development regions according to their levels of socioeconomic development. We then estimate a separate intergenerational regression coefficient for each region. We find that intergenerational education mobility is higher in regions with higher level of economic development. For instance, while one year increase in mothers' years of schooling is associated with a more than one year increase in daughters' years of schooling in the least developed region of Turkey, the same number is 0.6 in the most developed region. Moreover, when we estimate the relationship between education mobility and development for males and females separately, we find that this relationship is much stronger for the female subsample. In fact, when we conduct robustness exercises in which we partition Turkey into 5, 10, 20, and 25 regions (instead of 15), the relationship between mobility and development remains consistently significant across these exercises only for females. These results confirm our findings in the parametric case that education mobility varies significantly with economic development, and this is especially true for females.

\footnotetext{
${ }^{5}$ See Elango et al. (2015) for an excellent review of the empirical literature on the importance of early childhood education for adult outcomes.
} 
It is important to stress that the evidence we provide regarding the positive relationship between economic development and mobility is descriptive and does not identify any causal mechanisms. Yet, we believe that the correlations we calculate here are valuable because they can guide future research that aims to identify such mechanisms.

Finally, we also compute correlations of our mobility estimates with characteristics of childhood environments across regions. Specifically, we focus on four characteristics of the environments in which people grew up in: availability of educational facilities, cultural attitudes toward women, highest level of education among relatives, and the extent of educational inequalities. Our findings indicate that high mobility areas are characterized by higher supply of schools and more favorable gender culture toward women. We also find that intergenerational mobility is higher in regions where the years of schooling of the relative with highest education is higher. Moreover, interestingly, we find that a Great Gatsby curve exists in education: regions with lower educational inequalities also feature higher mobility.

Literature review This paper contributes to an extensive literature on intergenerational mobility. ${ }^{6}$ Hertz et al. (2007) conduct an impressive survey study which allows for international comparison of intergenerational mobility across countries. As Hertz et al. (2007) point out, even though there is an abundance of intergenerational educational mobility studies for developed countries, there are only a few studies that measure mobility for developing countries due to data limitations. By providing intergenerational mobility measures for Turkey, therefore, we contribute to the growing literature of developing country studies. ${ }^{7}$

\footnotetext{
${ }^{6}$ See Solon (1999) and Black and Devereux (2011) for excellent reviews of this literature.

${ }^{7}$ Most studies of intergenerational education mobility in Turkey use samples that consist of children who still reside with their parents, and hence, might have not completed their educational attainments. See, for instance, Tansel (2002), Kırdar (2009), Uysal-Kolaşin and Yontar (2012). Özdural (1993) and Korkmaz (2005) are exceptions that target specific cities, Ankara and Malatya, respectively. In a concurrent paper, Tansel (2015) uses the 2007 Adult Education Survey and reports estimates of intergenerational education mobility by age cohorts. She finds some evidence of increased mobility for the younger generations of children in Turkey.
} 
Our paper also contributes to a burgeoning literature on multigenerational mobility, which analyzes the persistence of economic outcomes across three or more generations (see Solon 2015 for an excellent review). Behrman and Taubman (1985) estimate regressions of children's years of schooling on parents' and grandparents' and find grandparents' years of schooling have regression coefficients that are very small and statistically insignificant. Ridge (1974), Warren and Hauser (1997) and Kerr and Lucas (2013) confirm the findings of Behrman and Taubman (1985) using data from U.K., U.S. and Finland, respectively. ${ }^{8}$ Lindahl et al. (2015) use Swedish data to estimate a three-generation earnings regression and find that the regression coefficient of grandfather's earnings is statistically significant. There is little work on multigenerational mobility in developing country contexts. One such example is Zeng and Xie (2014) who study the effects of grandparent's on children's schooling within the context of rural China and find that living with well-educated grandparents significantly reduces children's likelihood of school dropout.

Our analysis of how mobility changes with socioeconomic development is related to Chetty et al. (2014) who find that intergenerational mobility varies significantly over geographic areas in the United States. They show that high mobility areas have less residential segregation, less income inequality, better primary schools, greater social capital, and greater family stability. More recently, Guell et al. (2015) analyze intergenerational income mobility in 103 Italian provinces. Using the large heterogeneity across Italian provinces in terms of economic and social outcomes, the authors document that higher income mobility is correlated with good economic outcomes such as higher value added per capita, higher employment, and higher schooling. Importantly, however, they use information on children's current place of residence in their analysis, and as our results suggest, this may not be very informative about the relationship between mobility and economic environment children live in while growing

\footnotetext{
${ }^{8}$ Similar results are reported by Jaeger (2012) within the US and Chiang and Park (2015) within the Taiwanese context. These studies also consider the heterogeneity in the grandparent effect by parents' characteristics.
} 
up. Our paper is also related to a recent paper by Chetty and Hendren (2016) who investigate the extent to which children's opportunities for upward economic mobility are shaped by the neighborhoods in which they grow up in the United States. The authors show that various characteristics of childhood environments have significant causal effects on adult outcomes.

\section{Methodology}

The main aim of the studies in intergenerational education mobility is to understand the degree to which offspring's educational outcomes depend on their parents' educational outcomes. Due to data limitations, most studies in this literature use information on the highest degree completed to measure people's educational outcomes. Another, finer, measure of educational attainment is completed years of schooling. The latter measure of educational attainment has two possible merits relative to the former. First, obviously, completed years of schooling is a more precise measure of educational attainment, and this precision might be especially important if additional years of schooling attained before dropping out has significant returns in the labor market. Second, completed years of schooling is more of a continuous variable compared to highest degree completed, and as such allows for regression analysis. Motivated by these merits of completed years of schooling as a measure of educational attainment, our survey is carefully designed to extract information on additional years of schooling completed from dropouts. As a result, we have data on completed years of schooling and that is the main educational outcome variable we use throughout the paper.

There are two well-known average measures of intergenerational education mobility: the regression coefficient and the correlation coefficient. These measures are simple statistics that inform us about the average predictive power of parental education on children's education. The regression coefficient, $\beta$, is obtained by regressing children's years of schooling $S_{1}$ on parent's years of schooling $S_{0}$ : 


$$
S_{1}=\alpha+\beta S_{0}+e
$$

This measure has the merit of being easily interpretable: it represents the average increase in children's years of schooling that occurs when parental years of schooling increases by one year. As such, the regression coefficient tells us how strong the association is between parent's and offspring's education.

The correlation coefficient, on the other hand, is a mobility measure that is informative about the association between a parent's rank in the parental education distribution and a child's rank in their own education distribution. In order to compute the correlation coefficient, which we denote by $\beta^{a}$ throughout the paper, we first adjust the parents' and children's distributions of years of schooling to equate the standard deviations of these distributions. We do so by dividing the years of schooling variable for children by the standard deviation of children's years of schooling distribution. This gives us an adjusted years of schooling variable for children, denoted by $S_{1}^{a}$, which is distributed with a standard deviation of one. We repeat the same procedure and create adjusted years of schooling variable for parents, denoted by $S_{0}^{a}$, whose distribution also has a standard deviation of one. Then, we conduct the following regression analysis:

$$
S_{1}^{a}=\alpha^{a}+\beta^{a} S_{0}^{a}+e
$$

The regression coefficient $\beta^{a}$ represents the standard deviation increase in children's years of schooling rank that occurs when parents' years of schooling rank increases by one standard deviation. The correlation coefficient is related to the regression coefficient as follows:

$$
\beta^{a}=\beta \frac{\sigma_{0}}{\sigma_{1}}
$$


where $\sigma_{0}$ and $\sigma_{1}$ denote the standard deviations of parents' and children's unadjusted years of schooling distributions, respectively.

Notice that the correlation coefficient can be especially useful as a measure of intergenerational mobility if we want to make comparisons across countries since both parents' and children's distributions can vary significantly across different countries. Similarly, the correlation coefficient might be a better measure if we are analyzing the evolution of mobility over time. A change in the regression coefficient might result from a change in relative distributions of parents' and offspring's generations over time whereas a change in the correlation coefficient, by definition, has to come from a change in how strong children's education is related to that of parents'.

\section{Data}

There is no data set in the Turkish context that provides the key information required for our analysis, such as the region of residence during various years of childhood development or educational attainment across multiple generations. Thus, we conducted a household survey across Turkey to construct the data set needed for our investigation. The survey questionnaire asks a total of about two hundred questions regarding the demographics, educational status, labor market status, and cultural attitudes of households.

Data collection The survey targets adult population, defined as individuals who are 18 years old or older. The number and the geographical distribution of the sampling units are determined so as to achieve representation of Turkey both geographically as well as across the rural/urban divide within each region. ${ }^{9}$ The resulting sampling frame used in our analysis

\footnotetext{
${ }^{9}$ The random sample of household addresses is provided by Turkish Statistical Institute (TUIK) based on the national registers (ADNKS 2013). The sampling procedure used by TUIK partitions Turkey into 26 regions, called NUTS 2 regions. There are 81 provinces in Turkey and a NUTS2 region typically involves a number of provinces (up to 5). For sampling purposes TUIK divides each NUTS2 region into blocks of 400 households and these blocks are further classfied as either an urban or a rural area of residence. The random sample of households is drawn in two steps. In the first step, a random sample of blocks is drawn from each NUTS2 region. In the
} 
includes addresses from 74 of 81 provinces. Within each household, the interviewee is also determined randomly. ${ }^{10}$ If the person chosen for the interview is not available on the first visit, the same address is visited two more times. If the interview cannot be conducted after three visits, the address is dropped from the sampling frame. The survey was conducted over November 2014 - February 2015 period and resulted in 4703 completed interviews. ${ }^{11}$

\section{Sample weights Household Labour Force Survey (HLFS), conducted by Turkish}

Statistical Institute (TUIK), is a representative sample of households in Turkey with around half a million observations in each cross-section. We construct sample weights to ensure that the unconditional distributions of age, gender and education that result from our survey match the corresponding distributions computed using HLFS 2013 data. We chose the 2013 survey because our sampling frame is based on the national registers data for that year (ADNKS 2013). Specifically, the sample weights ensure that the distributions of individuals in our sample over 13 age groups, five education categories, and two gender categories match those in HLFS. The use of sample weights is important because significant deviations in the distributions of these characteristics from a nationally representative sample such as HLFS may lead to biases in the nationwide estimates of intergenerational mobility if there are significant differences among mobility rates of population subgroups.

second step, a random sample of households is drawn from each block. The two-step procedure ensures representativeness of population across NUTS2 regions as well as across the urban/rural divide within each NUTS2 region.

${ }^{10}$ For a given household the interviewerer first produces a list of birth date information of all household members who are 18 and above. Then, the interviewer chooses as interviewee that household member whose day of birth (e.g. 20th of month X) is closest to the day of the month the interviewer first visits this address (e.g. 18th of month $\mathrm{Y})$.

${ }^{11}$ The field work for our survey was conducted by a private polling company. The response rate was $53 \%$ which is common for surveys conducted through polling companies within the Turkish context (as there is no obligation for respondents to complete the survey). Among the addresses that refused to respond, $96.2 \%$ rejected outright to talk to a polling company while for the remaining 3.8\% randomly chosen individual within the household rejected to respond. Thus, once the interview process reached the stage of randomly choosing the person to be interviewed the successful completion rate of the interview was $96.6 \%$. Being aware of low response rates for surveys conducted by polling companies, we have asked for a sample size of random addresses from Turkish Statistical Institute that is much larger than the target number of completed surveys. If the interview at a randomly chosen address could not be conducted after three attempts we did not allow for what is called "snow balling", where the interviewer choses an address nearby, as this technique may jeopardize randomness. The interviewers had to strictly stick to the random sample of household addresses provided to them and continue polling until all such addresses were visited. 
Our primary analysis sample includes all individualls in the base data set who are 25 years or older. We restrict our sample in this way to focus on individuals who finished their education. This sample, which we call the main sample, has 3500 observations.

Our main educational attainment variable is years of schooling. For all agents, this variable is defined as completed years of schooling. For example, if an individual reports that she dropped out after two years in high school, then her years of schooling is computed as $5+3+2=10$ years. (In Turkey, primary school and secondary school take five and three years to complete, respectively.) In addition to their own education level, survey respondents report their parents' and (all of) their children's educational attainments as well. Based on the retrospective questions about parental education, we compute parents' years of schooling.

There is another data set, namely Adult Education Survey (Yetiskin Egitimi Anketi), which provides information on educational attainment of children and parents in Turkey. ${ }^{12}$ Compared to AES, our survey data has three key advantages. First, our survey data contains much more detail on educational attainment of individuals. Second, our data includes province level information on the region of residence during various periods of childhood development (including current residence) while AES surveys only include information on current residence at a level of 21 broadly defined geographic regions. Finally, our data includes information on educational attainment across multiple generations while such data is not available in AES. Therefore, unlike our data, AES is adequate neither for analyzing the relationship between development and mobility nor for conducting multigenerational mobility analysis. Nevertheless, information on parental education from AES is useful to us as it provides a benchmark to compare the educational distribution of parents from our survey. The comparison yields a close match between the two surveys regarding parental education distributions. The only significant difference is observed at the bottom of the distribution of mothers' education

\footnotetext{
${ }^{12}$ AES surveys were conducted by TUIK in 2007 and 2012 to collect information on participation in adult learning activities.
} 
where in our sample the fraction of those with no education is relatively lower and the fraction with primary school education is higher; similar fractions are found for the other education categories. ${ }^{13}$

\section{Descriptive statistics $\quad$ Table 1 reports summary statistics for the main sample. Panel A}

of the table reports basic statistics for various demographic and educational characteristics. The mean age among survey respondents (whom we refer to as children in the two-generation analysis) is 45.4 years. The mean years of schooling among children and parents in this panel indicate a substantial increase in educational attainment across generations. For instance, while mean years of schooling is only about 4 years among fathers and it is 7 years among children.

Panel B of Table 1 provides further information on educational attainment by generation. The substantial increase in mean years of schooling across generations is also reflected in terms of educational attainment. For example, while the fraction of those with less than primary education is $38.5 \%$ among fathers, it decreases to $8.7 \%$ among male children. There is a parallel increase in the fraction of those with college or university degree. This fraction increases from $2.3 \%$ among fathers to $16.5 \%$ among male children. Similar improvements in educational attainment are observed among females although females in general have lower educational attainment than their male counterparts in the same generation. The comparison of male and female education by gender also indicates that the improvement in

\footnotetext{
${ }^{13}$ Parents' education categories in the public use micro data files of AES surveys are provided in three very broad categories (less than high school, high school, and more than high school). However, Tansel (2015) reports detailed education distributions by age cohorts for parents using confidential files of AES 2007. We compute the education distributions for fathers and mothers for the same birth cohorts using our data and compare them to those in AES 2007. Five educational attainment levels are available from the confidential AES survey: no degree holders, primary school (5 years of education), secondary school (8 years of education), high school, and above high school. The fraction of fathers in the AES survey (our survey) for these five education categories are $40.9 \%$ $(38.5 \%), 46.2 \%(47.9 \%), 5.1 \%(5.5 \%), 4.8 \%(5.8 \%)$, and $2.9 \%(2.3 \%)$ respectively. The fraction of mothers in the AES survey (our survey) for these five education categories are $62.6 \%$ (56\%), $31.9 \%(37.2 \%), 2.4 \%(2.5$ $\%), 2.1 \%(3.3 \%)$, and $0.9 \%(1.1 \%)$ respectively. There are also detailed tabulations provided in a publication by TUIK for AES 2012 survey (Yetişkin Eğitimi Araştırması 2012, TUIK, accessed on November 2015, www.tuik.gov.tr/IcerikGetir.do?istab_id=218). There are, however, some clear errors in the reported numbers. For example, among fathers, the fraction that completed primary education ( 5 years of education) is reported as $13.7 \%$ while the fraction that completed secondary education ( 8 years of education) is $52.7 \%$. These figures are at odds with the earlier AES 2007 survey, with the Household and Labour Force Surveys and our survey. Therefore, we don't provide any comparisons to figures reported in that publication.
} 
educational attainment is accompanied by an increase in education gender gap. For example, while the difference between females and males in the fraction of those with less than primary education (i.e. females-males) is 17.5 percentage points (pp.) among parents, it becomes 20.5 pp. among the children. This is also reflected at higher education levels. While the fraction of mothers with high school education or more is $3.8 \mathrm{pp}$. lower than fathers, this difference becomes 12.6 among children. To sum up, there has been a significant rise in educational attainment across two generations in Turkey; however, the underlying factors that led to these improvements have not equally benefitted males and females.

\section{Table 1 [about here]}

Given the importance of geography for our main analysis, we compare the geographical distribution of our sample across Turkey to the geographical distribution in HLFS. TUIK partitions Turkey into 12 broad regions called NUTS1 regions. Table 2 compares the fractions of people living in each region in our survey and HLFS 2013. Despite the much smaller size of our sample (about 1\% of the corresponding sample size in HLFS 2013 for individuals 18 and over) and the fact that our weights do not correct for the spatial distribution, we find that the two surveys feature very similar geographic distributions across Turkey.

Table 2 [about here]

\section{Intergenerational Education Mobility at the National Level}

\subsection{Baseline Estimates}

In this section, we present intergenerational mobility estimates at the national level. Figure 1 Panel A plots mean years of schooling of children as a function of fathers' years of schooling. The long-dashed line refers to the 45-degree line while the short-dashed vertical and horizontal lines mark the mean schooling of children and fathers. This nonparametric representation of the relationship between children's and fathers' years of schooling shows that the conditional 
expectation of children's years of schooling given fathers' years of schooling is approximately linear in fathers' years of schooling. ${ }^{14}$

Figure 1 [about here]

Partly motivated by the approximate linearity of the relationship in Figure 1, we estimate a regression of children's years of schooling on parents'. Column (1) of Table 3 presents the regression coefficient associated with fathers' years of schooling in the regression where we regress children's years of schooling on fathers' years of schooling using our main sample. The regression coefficient is 0.734 and is highly significant. This implies that an increase of one year in father's years of schooling is associated with about 0.7 years increase in child's years of schooling. Column (2) reports the regression coefficient for the specification where we regress children's years of schooling on mothers'. The regression coefficient of mothers' years of schooling, 0.767 , is similar in magnitude to the estimated coefficient for fathers' years of schooling, and is also highly significant. Finally, Column (3), which reports results for the regression analysis where both parents' education levels are present as independent variables, shows that the education levels of both parents are positively related to children's education. Just to provide a comparison, we also conduct the same mobility regressions using information from AES and find that our national level estimates are broadly in line with AES based estimates. ${ }^{15}$

Table 3 [about here]

\footnotetext{
${ }^{14}$ Formally, we also tried to fit a quadratic specification between mean child years of schooling and father's years of schooling; the coefficient of the quadratic term turned out to be insignificant.

${ }^{15}$ For estimation purposes, we pool 2007 and 2012 AES data and restrict the sample to individuals who are 25 years old or older as in our analysis. This results in around 56,900 observations. An important restriction of the AES data is that parent's education categories are very broadly defined in the public use files. In order to partly overcome this limitation, we use information on detailed education distributions from Tansel (2015), who uses confidential files of AES 2007, and assign years of schooling to parents. The regression coefficient of father's years of schooling is 0.724 (0.007) when we regress children's years of schooling on father's using AES data. This coefficient estimate is very similar to the estimate from our survey data $(0.734)$, but more precisely estimated given the fact that AES sample sizes are much higher. The regression coefficient of mother's years of schooling is 0.837 (0.011). This estimate is somewhat higher than the estimate obtained from our data $(0.767)$.
} 
It is interesting to compare Turkey to other countries in terms of education mobility. However, as explained in Section 2, using regression coefficients for such a comparison might be misleading. For this reason, we also compute correlation coefficients. Figure 1 Panel B presents a nonparametric representation of the relationship between mean adjusted years of schooling of children and fathers' adjusted years of schooling. Panel B shows that the conditional expectation of children years of schooling given fathers' years of schooling is approximately linear on fathers' years of schooling, a finding that supports the linear regression specification that delivers the correlation coefficient. Columns (4) and (5) in Table 3 report that the correlation coefficients between children's and fathers' and children's and mothers' years of schooling are 0.564 and 0.532 , respectively.

According to Hertz et al. (2007), South American countries feature the lowest education mobility in the world with a regional average intergenerational correlation value of 0.6 . The intergenerational correlations are typically about 0.4 in Western Europe, with the exception of Italy where the correlation is 0.54 . The lowest estimates in Europe belong to the Nordic countries. The U.S. estimate is 0.46 . These values imply that the mobility in Turkey is somewhat higher than the South American average but it is significantly below the developed countries of Western Europe and the United States. ${ }^{16}$

\subsection{Three Generation Education Mobility}

In our survey, we gather information on the educational outcomes of people's children as well as their parents. This information allows us to study intergenerational mobility across three generations. We first drop the observations in which the respondent has no children. We set the respondent's parents as the first generation, the respondent as the second generation, and the

\footnotetext{
16 The country-level correlation values reported here are taken from Table 2 on page 15 in Hertz et al. (2007). This paper provides correlations of average parental years of schooling with children's years of schooling. As such, these values are not readily comparable to our estimates of 0.564 and 0.532 . Just for comparability, we also compute the correlation between average parental years of schooling and children's years of schooling and find it to be around 0.6, which is closer to estimates for Latin American countries.
} 
respondent's children as the third generation. If the respondent has multiple children, we treat each child with the corresponding parents and grandparents as a separate observation and cluster standard errors at the family level. ${ }^{17}$ We drop the observations in which the children are less than 25 years old as they might not have completed their education by that age. Moreover, we focus on grandfathers as the first generation and exclude grandmothers completely from our regressions. We do so mainly because there is too little variation in the years of schooling of grandmothers. $^{18}$

We summarize our results in Table 4. The first and second columns of the table report results of regressions in which the only independent variables are father's years of schooling and paternal grandfather's years of schooling, respectively. ${ }^{19}$ The second column shows that grandfather's years of schooling has a positive and significant relationship with children's years of schooling. The third column displays results of the analysis in which we regress children's years of schooling on father's and grandfather's years of schooling at the same time. The regression coefficient associated with grandfather's years of schooling loses its significance when we control for father's years of schooling. This means that grandfathers' educational outcomes are associated with children's educational outcomes only through fathers'. Columns $(5)-(8)$ of Table 4 report the results of the three-generation regressions in which the parent is a mother. Column (7) shows that the regression coefficient of the maternal grandfather's years of schooling remains significant even after we control for mothers' years of schooling. Following Braun and Stuhler (2017), we test for a causal effect of maternal

\footnotetext{
${ }^{17}$ Note that for a representative sample of third generation it is necessary in our case to use information on each child of survey respondent. If instead, for example, we randomly choose one of the children of each survey respondent (when the respondent has multiple children) this would lead to a discrepancy in family characteristics of third generation between our sample and that in the population -such as in terms of the distribution of the number of siblings.

18 The average age of respondents with a randomly chosen child of at least 25 years old is 61 in our sample which implies an average age of around 85 for grandmothers for this restricted sample. The educational attainment of women in that age cohort is very low and shows little variation in Turkey. For example, $95 \%$ of all the grandmothers in the sample of the three-generation analysis have either 0 or 5 years of schooling. ${ }^{19}$ The father-child regression coefficient reported in the first column of Table 4 is different from the corresponding coefficient in the first column of Table 3. This is because the sample we use for three generation mobility analysis is quite different from our main sample. A similar difference across estimates is also present in mother-child regressions for the same reason.
} 
grandparent's educational attainment on children's educational attainment by adding father's years of schooling to the maternal grandfather-mother-child regression. ${ }^{20}$ The results are reported in Column (8). The inclusion of father's education turns the maternal grandfather's education insignificant, implying that the effect of grandfather's education on children is more likely to be spurious than causal.

\section{Table 4 [about here]}

\subsection{Transition matrices}

Regression and correlation coefficients are very useful statistics that summarize the dependence of children's educational outcomes on parents' educational status on average. However, they do not provide information about how strong this dependence is at different segments of the education distribution. In this section, we present transition matrices that estimate mobility patterns across the education distribution. An education transition matrix is a matrix whose rows and columns correspond to education levels of parents and children, respectively. For a given row $\mathrm{i}$, the value in each column $\mathrm{j}$ represent the fraction of children that attain education level j given that their parents' education level is i. Due to limitations regarding the size of our data, in all the transition matrix analyses, we group individuals into four categories based on their education level. "Less than primary education" category includes those who attended primary school but did not obtain a diploma, those who never attended formal school but are literate, and those who are illiterate. "Primary/lower sec" category includes individuals who have a primary or a lower secondary school degree. "HS" group

\footnotetext{
${ }^{20}$ Warren and Hauser (1997) is the seminal study that includes both parents' educational outcomes in three generation regressions to test for causal effects of grandparent's educational attainments. As Braun and Stuhler (2017) explain, this test only allows us to reject direct grandparent effects. If we continue to find a positive maternal grandparent effect in regressions that condition on the status of both parents, we still cannot rule out that other omitted parental characteristics are driving the result.
} 
refers to people with a high school diploma and "College or univ" category includes individuals with at least a two-year college degree..$^{21}$

The father-child and mother child transition matrices are presented in the top and bottom panels of Table 5, respectively. If there were perfect intergenerational mobility in educational attainments, all the rows would be identical in each transition matrix. A comparison of the rows of the father-child transition matrix clearly shows that the distribution of education outcomes for children depend on their fathers' level of education, confirming our earlier findings. The same is true when one considers the mother-child transition matrix.

Table 5 [about here]

A closer look at the parent-child transition matrices of Table 5 reveals that intergenerational persistence is especially pronounced at the top of the education distribution: children who are born to fathers with a college degree have $71 \%$ probability of receiving a college degree themselves. We discuss two other measures of mobility that we deem important. The first one is the probability that a child stays at the bottom of the education distribution (Less than primary education) when the parent is at the bottom of the education distribution. This measure, which we call bottom-to-bottom probability throughout the paper, summarizes the degree of persistence at the bottom of the education distribution. We see from the first row first column of the father-child transition matrix that bottom-to-bottom probability is about $38 \%$. The other measure we focus on is the bottom-to-top probability, which measures the probability that a child belongs to the top education category (college or university education) when the parent/grandparent is at the bottom of the education distribution (less than primary education). The father-child matrix shows that this simple measure of success is quite low at $3.44 \%$. These findings remain qualitatively valid when one considers mother-child transition matrix as well.

${ }^{21}$ In the Turkish context college refers to a two-year while university refers to a 4-year post-secondary education. 


\subsection{Intergenerational Education Mobility by Gender}

In this section, we assess whether intergenerational persistence in education differs by gender. To do so, we conduct the following regression analysis on our main sample:

$$
S_{1 i}=\alpha+\beta_{0} S_{0 i}+\beta_{1} S_{0 i} * G_{i}+\beta_{2} E_{i}+e_{i}
$$

Here, $S_{1}$ and $S_{0}$ represent individual's and parent's years of schooling as before. $G$ is a dummy variable that takes value 1 if the individual is female and 0 otherwise, and $E=1-G$. In this regression, $\beta_{0}$ measures the increase in children's years of schooling when parents' years of schooling increases by one year while $\beta_{1}$ measures the additional change in the years of schooling of the offspring associated with one year increase in parental education if the offspring is female.

Column (1) of Table 6 reports the results of the regression analysis given by Equation (4) for the case where we take father's years of schooling as the parental education input. We find that the coefficient of the interaction term is positive and statistically significant, implying that the regression coefficient between fathers' and daughters' years of schooling is significantly higher than the coefficient between fathers' and sons'. Column (2) reports the same qualitative result for the case in which parental input is mother's years of schooling. Finally, we run the same exercise this time including both father's and mother's years of schooling as parental inputs. ${ }^{22}$ Interestingly, as Column (3) displays, this time we find that among the interaction terms only the variable that we create by interacting mother's years of

\footnotetext{
${ }^{22}$ To be precise, we estimate the equation $S_{1 i}=\alpha+\beta_{0} F_{i}+\beta_{1} F_{i}^{*} G_{i}+\beta_{2} M_{i}+\beta_{3} M_{i}{ }^{*} G_{i}+\beta_{4} E_{i}+e_{i}$, where F, M, G, and E stand for father's years of schooling, mother's years of schooling, female dummy and male dummy, respectively.
} 
schooling and the female dummy variables is statistically significant. Namely, one year increase in mother's years of schooling is associated with about 0.2 years increase in son's education whereas it is associated with almost 0.5 years increase in daughter's education. This suggests that it is indeed the case that intergenerational education mobility is lower for females than males and the channel that creates the extra persistence in educational attainments of parents and daughters is mainly working through mothers. ${ }^{23}$

Table 6 [about here]

\section{Education Mobility and Socioeconomic Development}

There is substantial heterogeneity across regions in Turkey regarding various aspects of socioeconomic development. For instance, GDP per capita in the most developed region, Istanbul, is more than three times as large as it is in a group of least developed provinces. Similarly, average years of schooling is more than twice in Istanbul relative to the same set of provinces. $^{24}$ This large regional variation enables us to study how intergenerational mobility in education changes with the level of socioeconomic development. To do so, we conduct two separate analyses. The results from both analyses show that education mobility is higher among females who grow up in more developed regions. That is, educational outcomes of daughters are related to their parents' educational outcomes to a lesser degree when they grow up in more developed regions. Interestingly, we do not find strong evidence for a similar relationship between development and mobility for males. We also find that the development level of place of residence during earlier stages of childhood has much stronger association with mobility than development level of place of residence during later stages. Finally, we compute correlations of intergenerational education mobility estimates with regional

\footnotetext{
${ }^{23}$ We also run three-generation mobility regressions by gender and find that the coefficient of grandparents' years of schooling is statistically significantly higher for daughters than sons.

${ }^{24}$ See Table A1 and Table A2 in the Appendix for more information on how development characteristics compare across regions in Turkey.
} 
characteristics. While this exercise cannot determine causal mechanisms, it provides important insights regarding the importance of several correlates for intergenerational mobility.

\subsection{Socioeconomic Development}

We begin by explaining how we measure socioeconomic development level of the places where individuals grew up in our sample. Turkey is divided into 81 administrative areas called provinces. The Turkish Ministry of Development periodically measures the level of socioeconomic development at the province level. As part of the measurement process, the ministry has developed an index that aims to summarize the level of development in each province. This index combines 61 distinct measures of socioeconomic development that can be classified under eight categories: demographics, employment, education, health, competitiveness and innovation, financial development, transportation and telecommunication availability, and quality of life. Larger values of this index indicate higher level of socioeconomic development. ${ }^{25}$ In our analysis, we use the most recent index, SEGE-2011, which stands for Socio-economic Development Index for 2011, as a proxy for the development level of each province.

Our data includes separate information about the province of residence when individuals were between ages of 0-6, 7-12, and 13-18, as well as, the current place of residence. ${ }^{26}$ Since we are interested in people's educational attainment, the characteristics of the place where they grew up matter more than the characteristics of the current place of residence. For this reason, we assign each individual to the province he or she resided while growing up (from birth till age 18). Individuals who lived in multiple provinces during this

\footnotetext{
${ }^{25}$ SEGE-2011 index has a mean value of zero and a standard deviation of one. See Kalkinma Bakanligi (2013) for detailed information about how the index is constructed.

${ }^{26}$ If a respondent lived in more than one province during a certain age interval, then the survey asks them to single out the one they lived the longest. That is the province of residence we use for that age interval.
} 
time are assigned to the province they resided between the ages of 7 and 12 in our baseline exercise. For robustness, we also conduct exercises in which we assign individuals to their province of residence during the ages of 0-6 and 13-18, and their current place of residence. In the estimations of Sections 5.2 and 5.3, we include all individuals in the base data set who are 20 years or older. The main rationale for expanding the lower age limit is to increase the precision of estimates reported for each development region in Section 5.3. ${ }^{27}$ The resulting sample of survey respondents has 4308 observations.

\subsection{Parametric Specification}

Our first analysis of the relationship between mobility and development takes a parametric approach. We extend the basic intergenerational regression equation (1) by adding an independent variable: an interaction term between parents' years of schooling and the socioeconomic development level of the province where children grew up. The equation that we estimate for the parent-child years of schooling relationship becomes:

$$
\mathrm{S}_{1 \mathrm{i}}=\alpha+\beta_{0} S_{0 i}+\beta_{1}\left(S_{0 i} * \operatorname{DevInd}_{i}\right)+\gamma \operatorname{DevInd}_{i}+\varepsilon_{i}
$$

where $\operatorname{DevInd}_{i}$ is the development index score for individual $i$ 's place of residence between ages of 7 and 12. Notice that using SEGE-2011 to determine the socioeconomic development level of provinces where people grew up assumes that the development rank of a given province in 2011 provides a good proxy for that province's development rank when individuals were between the ages of 7 and 12. In our context, this is not a strong assumption because the

\footnotetext{
27 The primary analysis sample we have used until this section includes individuals who are 25 years or older. When we replicate the analysis of Section 5 using our primary analysis sample, we obtain very similar results to those reported in this section. Similarly, when we replicate our main mobility estimates reported in Section 4 with the sample age limit set to 20 as we do in the current section, we obtain results very similar to those reported in Section 4. For example, Table 2 reports regression coefficient estimates of $0.734(0.018)$ for father's education and $0.767(0.021)$ for mother's education in columns 1 and 2 . The corresponding estimates are $0.765(0.016)$ and 0.799 (0.019) when the sample includes individuals 20 years of age and older.
} 
development ranks of Turkish provinces are very persistent over time. ${ }^{28}$ Since development index varies at the province level we cluster standard errors at province level (81 provinces) in regressions that we report in this section.

The estimation results for equation (5) are presented in Table 7. The first column named Father-all refers to the regression specification in which parental education variable is fathers' years of schooling and the sample includes all observations in our main sample. The next five columns are defined similarly. The third row of Table 7 reports the coefficient estimates for $S_{0 i} *$ DevInd $_{i}$ interaction term, which is our main variable of interest. Looking at the third row of first and fourth columns, we see that the coefficients are negative and significant, indicating that the relationship between parents' years of schooling and children's years of schooling is weaker in places with higher levels of economic development. In other words, educational outcomes of children who grew up in more developed provinces depend less on their parents'.

A closer look into Table 7 reveals an interesting caveat, however. The coefficients of the interaction terms in the regressions where the sample is restricted to males (Columns 2 and 5) are close to zero and insignificant whereas those for the female sample are significantly negative (Columns 3 and 6) and large in absolute value. These results imply that the level of development has a positive relationship with the intergenerational education mobility of females whereas such a relationship does not exist for males. As a side note, notice that the estimate of $\gamma$ that refers to DevInd variable is much higher in father-daughter and motherdaughter regressions than it is in father-son and mother-son regressions, indicating that a rise in development increases female children's years of schooling much more than male children's.

\footnotetext{
${ }^{28}$ The development ranks and indices of provinces are also available for the years 1985, 1996 and 2003. We compute the correlation of province development ranks across years and find the correlation to be 0.94 between 1985 and 2011, 0.97 between 1996 and 2011, and 0.98 between 2003 and 2011. The corresponding correlations for development index values are $0.91,0.96$ and 0.97 respectively. We prefer to use the 2011 index because the number of provinces increased from 67 to 81 during the 1980-2000 period due to newly established provinces and the survey captures the place of residence information based on the new list of provinces. There have also been several improvements in the methodology of generating the development index values reflected in SEGE-2011. See Kalkinma Bakanligi (2013) for details.
} 
Table 7 [about here]

Recall that in our baseline analysis we assign individuals who live in multiple provinces while growing up to the province they resided between the ages of 7 and 12 . We also conduct exercises in which we assign such individuals to their province of residence during the ages of 0-6 and 13-18, and their current place of residence. Table 8 summarizes our findings. The third row of the table reports the coefficient estimates for $S_{0 i} *$ DevInd $_{i}$ interaction term, which is again our main variable of interest. The first four columns report the results for the Fatherdaughter specification. The third column displays the benchmark analysis in which the area of residence is defined as the province individuals resided during the ages of 7-12.

A comparison of the first four columns reveals that the development level of place of residence has much stronger association with mobility when we define place of residence as the place of residence during the ages of $0-6$ and 7-12 rather than the place of residence during the ages of $13-18$ (-0.058 and -0.056 vs. -0.033$)$. The development level of area of residence has the weakest association with mobility when place of residence is taken to be the individual's current area of residence (-0.029). An identical pattern is observed when one instead considers the results regarding the Mother-daughter specification, which are reported in Columns (5) - (8) of Table $8 .{ }^{29}$ We conclude that the development level of the place of residence during earlier years of childhood is more significant for daughters' mobility than their areas of residence in later years. This conclusion is in line with the recent empirical literature that shows the importance of the environment children live in early in life.

Table 8 [about here]

\footnotetext{
${ }^{29}$ We do not report the results of Father-son and Mother-son pairs because, as expected from our baseline findings, the relationship between development and mobility for sons is insignificant independent of which definition of area of residence we use.
} 
The fact that current area of residence is significant might be due to the fact that many of the individuals in our sample have been residing in the same province all their lives. In fact, when we restrict our sample to those whose current place of residence is different from place of residence during the ages of 0-6 and 7-12, we find that the association between the development level of current place of residence and intergenerational mobility becomes insignificant. As expected, the association between development and mobility remains strong when the place of residence is taken to be the individual's place of residence during the ages of 0-6 and 7-12 in this migrant sample. The results of this analysis are reported in Table 9. This finding suggests that using information on current area of residence might be misleading in estimating the relationship between mobility and development, and this problem can be severe depending on the extent of geographic mobility across regions.

\section{Table 9 [about here]}

\subsection{Nonparametric Specification}

The analysis carried out in equation (5) assumes a specific parametric relationship between mobility and development. In this section, we provide further support to the relationship between economic development and education mobility by conducting a nonparametric analysis in which we estimate intergenerational regression coefficients at a regional level. Due to limitations regarding the size of our sample, we do not run a separate regression for each province. Instead, we group provinces into 15 regions that have similar socioeconomic development index values, and estimate education mobility at the regional level. By construction, each region consists roughly $1 / 15$ of all the individuals in the sample. We have on average 290 observations in each development region. Appendix explains the procedure we use 
to group provinces into development regions in detail. It also includes Table A1 that presents the list of provinces within each development region. ${ }^{30}$

Figure 2 presents mobility estimates for each region. The top left panel depicts how the level of persistence between fathers' and children's years of schooling changes with economic development. Each blue dot represents a development region. The horizontal axis indicates the mean development score of the region whereas the vertical axis indicates the regression coefficient of fathers' years of schooling estimated for that region. The red-green band provides $95 \%$ confidence for the corresponding estimate of the regression coefficient. The orange line provides a linear fit to the estimated regression coefficients. The bottom left panel of Figure 2 displays the same graph taking mothers' years of schooling as the independent variable in the intergenerational education regression. Both graphs show that there is a significant and negative association between the level of development and the intergenerational persistence in education, confirming our earlier findings. For instance, a closer look at the graph on the top left panel of Figure 2 reveals that one year increase in fathers' years of schooling increases children's years of schooling by around 0.9 years in the least developed region whereas the same number in the most developed region (Istanbul) is about $0.6 .^{31}$

The top right panel displays how the level of persistence between fathers' and daughters' years of schooling changes with economic development. The bottom right panel shows the same relationship for the mother-daughter specification. We see that there is a significant negative association between development and intergenerational persistence in education for daughters. The top middle and bottom middle panels display the relationship

\footnotetext{
${ }^{30}$ It is important to note that while this procedure collects provinces that are similar in terms of their levels of development in a group, it does not necessarily imply geographic proximity between provinces within a group. For example, for development group 10, while Adana is located in Southwestern Turkey, another province in this group, Sakarya, is located in Northwestern Turkey.

${ }^{31}$ In the section entitled "An international comparison", we show that a similar negative association holds between intergenerational correlation coefficient and the development index, which implies that the intergenerational regression coefficient does not vary with development only because the distribution of educational attainment varies with development.
} 
between development and intergenerational persistence for sons. Interestingly, we find that for male children the association between mobility and economic development is less significant than that for female children. In fact, when we conduct alternative regional exercises in which we group provinces in Turkey into 5, 10, 20, and 25 regions (instead of 15 as it is in the benchmark analysis), we find that the positive association between development and mobility remains consistently statistically significant across all exercises only for females. This provides further support to our finding in the parametric analysis that the relationship between development and mobility is primarily important for females.

Figure 2 [about here]

An international comparison In this section, we compare the mobility estimates in our 15 development regions to those in the rest of the world as reported in Hertz et al. (2007). For purposes of this comparison, we follow the methodolgy of Hertz et al. (2007) and set average years of schooling of parents as the parental education variable. We also restrict the sample to individuals who are between the ages of 20 and 69 following Hertz et al. (2007). We estimate the correlation between the average years of schooling of parents and children's years of schooling for each region. Table A3 in Appendix lists these correlations for all regions. ${ }^{32}$

Figure 3 presents a heat map of the correlations across Turkey. Lighter colors represent higher levels of mobility. A quick glance at the figure reveals that the more socioeconomically developed Western regions of Turkey feature lighter colors, and hence, higher mobility. Moreover, we see that there is significant heterogeneity in intergenerational mobility across the country. On the one hand, intergenerational education correlation is higher than 0.75 in the least developed region (that consist of the seven provinces in darkest color). This is a degree of persistence in education that is much higher than the least mobile country as it is reported in

\footnotetext{
${ }^{32}$ We compute the correlation coefficient between average parental years of schooling and children's years of schooling after adjusting each of these variables by their respective standard deviations. Similar to our results in Figure 2 there is a strong relationship between the level of development and this alternative measure of mobility. A regression of the correlation coefficient on mean development index yields an estimated slope coefficient of 0.0524 with a standard deviation of 0.012 .
} 
Table 2 of Hertz et al. (2007), Peru, with correlation of 0.66. On the other hand, the intergenerational correlation is as low as 0.34 in the most mobile region, which is comparable in magnitude to the relatively higher mobility countries of Europe such as Sweden or Belgium. It is important to note that the only goal of this international comparison is to provide a sense of the magnitude of regional differences in education mobility across Turkey; we do not mean to compare the magnitudes of education mobility between regions in Turkey and other countries as the mechanisms determining mobility in a region of a country vs. a whole country might be quite different.

Figure 3 [about here]

The results in this section indicate that there are large differences across regions in intergenerational mobility. These differences in intergenerational mobility across regions have an important implication for the intergenerational mobility literature. There has been a long debate on the origins of intergenerational correlations (see for example Sacerdote, 2002). Some studies emphasize the role of nature in the transmission of economic outcomes across generations while others focus on the importance of nurture (family investments, institutions, social environments, among others). Given that this study is conducted within a single country where the inheritability of genes is unlikely to vary significantly across regions, the regional variation in the estimated intergenerational mobility coefficients provides evidence for the role of nurture in shaping mobility. ${ }^{33}$

\footnotetext{
${ }^{33}$ Turkey consists of two main racial groups: Turks and Kurds. There is no official statistic on the fraction of Kurdish population in Turkey. According to the three surveys by KONDA, a public opinion research and consultancy company conducted over the 2006-2013 period, the fraction of Kurdish people in the entire population ranges from $15.7 \%$ to $18.3 \%$. These estimates are based on the reported mother tongue. (http://www.radikal.com.tr/yazarlar/tarhan-erdem/turkiyede-kurtler-ne-kadardir-2-1130993/). Using the same definition, the fraction of Kurds in our sample is about $15.3 \%$. Moreover, Kurds dominantly live in the Eastern provinces of Turkey. To investigate whether the lower intergenerational mobility found in these regions are related to the racial composition of these regions, we also estimate mobility for the two racial groups separately. We find no statistically significant difference between the mobility of Turks and Kurds, which strengthens the case for the role of nurture in shaping mobility. We have also replicated our parametric and non-parametric analysis reported in Sections 5.2 and 5.3 by excluding individuals of Kurdish ethnic origin. All results remain qualitatively the same for this restricted sample. We exclude a detailed discussion of the analysis of mobility by ethnicity from this paper for the sake of brevity.
} 
Several mechanisms may lead to lower mobility in less developed regions. These regions may be characterized by lower educational opportunities due to, for example, lower supply of schools and higher costs of access to schooling. Therefore, in the context of less developed regions, parental investments may play a more significant role in shaping children's educational outcomes in comparison to more developed regions. Also, in less developed regions gender culture may be less favorable for female education and employment. Parental education may, therefore, be playing a more important role for overcoming these challenges in less developed regions. Although we cannot identify such causal mechanisms, in the next section, we investigate several important factors that may give rise to the correlation between the level of development and intergenerational mobility established in this section.

\subsection{Correlates of Intergenerational Mobility in Education}

In this section, we want to take a first step toward understanding why education mobility is positively associated with development. To do so, we compute correlations of our mobility estimates with characteristics of childhood environments across 15 development regions defined in Section 5.3. Our data set allows us to characterize childhood environments between the ages of 7 and 12 at the individual level. We then aggregate this information to construct regional averages of various childhood environment characteristics. Specifically, we focus on four groups of characteristics: availability of educational facilities, cultural attitudes toward women, highest level of education among relatives, and educational inequalities in each region. As opposed to using aggregate regional statistics based on other data sources, this approach has the advantage of providing a more accurate portrayal of environments children in our sample were exposed to while growing up.

\section{Availability of educational facilities We have two variables that measure the}

availability of educational facilities at the regional level. The first one measures the availability of middle schools in a given development region. Our survey asks individuals whether there 
was a secondary school present in their area of residence when they were between the ages of seven and twelve. For a given development region, we compute the value of this variable as the mean of the dummy variable that equals 1 if the individual reports the presence of a middle school and 0 otherwise. The second variable measures the availability of high schools in a given development region and is computed using the same methodology. The second row of Table 10 presents the results of a regression analysis in which the independent variable is our regional secondary school availability variable and the dependent variable is the regional intergenerational regression coefficient estimated in Section 5.3 for Father-all, Father-son, Father-daughter, Mother-all, Mother-son, and Mother-daughter pairs, respectively. Similarly, the third row of Table 10 reports estimates of the association between high school availability and intergenerational persistence. ${ }^{34}$ The results indicate a negative correlation between intergenerational persistence in education and school availability for daughters. To the contrary, we do not find a significant relationship between persistence and school availability for sons. These results echo our findings from Section 5.3 that higher development is associated with lower persistence, especially for daughters.

A mechanism that would give rise to the negative correlation between intergenerational persistence in education and school availability for daughters might be the following. In regions where nearby schooling facilities is a rare event, parents have to either send their children to distant places or arrange for housing around available schools. This would mean there are additional costs of sending children to schools in areas that are deprived of schooling.

\footnotetext{
${ }^{34}$ Each estimate in Table 10 is essentially a result of a two stage regression. The first stage is the estimation of intergenerational correlation coefficient for each region (as explained in Section 5.3). The resulting 15 regional estimates are used as the dependant variable in the second stage regression. The second stage involves a separate regression of this dependant variable on each of the region specific characteristics. Hence, there are 15 observations in each regression. Heteroscedasticity is a concern in this second stage regression since the regions have (slightly) different sample sizes and potentially other unobserved common characteristics. We perform heteroscedasticity tests along the lines of Solon et al. (2013) and find evidence of heteroscedasticty. Thus, to account for heteroscedasticity Table 10 reports results that use sample size of each region as weights - as is commonly done in the literature. We have also repeated our estimations using two alternative methods for correcting heteroscedasticity; using as weights the inverse of the sampling variances of the estimated correlation coefficients in the first stage and using weights proposed by Dickens (1990). Our results remain qualitatively the same with these alternative methods.
} 
These additional costs might be prohibitively high in terms of sending all children to school in cases of families with low education and, hence, income (especially in the presence of borrowing constraints). In such circumstances, it is very likely that the educational attainment of sons would be a priority over that of daughters (see for ex. Kingdon (2005) for evidence of bias in educational resource allocation in the Indian context). In more educated families with possibly higher financial resouces, both sons and daughters may attend schools. This introduces an additional channel through which educational outcomes of parents would covary with educational outcomes of daughters in areas with lower availability of schooling. This can also provide a partial explanation to why intergenerational persistence is higher for daughters in less developed regions. As columns 7 and 8 of Table A2 in Appendix reveals, unavailability of schooling facilities is more prominent in less developed regions, indicating this additional channel for intergenerational persistence might be more prevalent in those regions.

Gender culture In developing country contexts gender culture and social norms against female education and employment may have effects on the educational attainments of women (King and Hill, 1993). We construct a gender culture variable using our survey data that aims to measure such norms. Specifically, the survey asks respondents how much say they had in choosing their spouses. The set of answers can be grouped into two categories: the first category includes answers that indicate that the individuals themselves had the most say whereas the second category includes answers that indicate it was the family's opinion that counted the most. We construct a dummy variable that takes the value 1 if the answer is in the first category and 0 if it is in the second. Then, for each region, we compute the mean of this variable. Thus, the higher this gender culture variable is for a region, the larger is the say of people in their own marital decisions (as opposed to their families). The underlying assumption is that this variable is correlated with cultural attitudes against female education; that is, places in which people have a higher say in their marital situation also feature more favorable climates for female education and employment. The fourth row of Table 10 reports how 
intergenerational persistence in education changes with our gender culture variable across regions in Turkey. We find that in regions where gender culture is more favorable toward women intergenerational mobility is higher for daughters. We find no such effect of gender culture on mobility of males.

Why is it the case that regions that feature more favorable gender culture also feature higher mobility for daughters? One explanation might be that social norms that are against female education and employment introduce additional non-pecuniary costs for parents to send their daughters to school. Under the assumption that these costs are higher in families where parents are less educated, gender culture introduces a further channel of intergenerational persistence between educational outcomes of daughters and their parents. One may expect this additional channel of persistence to be stronger in regions where gender culture is less favorable toward females. This may also provide a partial explanation to why intergenerational persistence is higher for daughters in less developed regions. Column 9 of Table A2 shows that our gender culture variable, the fraction of people who choose their spouses, is higher in regions that are more developed, implying this additional channel might be stronger in less developed regions.

\section{Highest years of schooling among relatives The availability of family members with} high levels of education may constitute an important characteristic of childhood environments (see, for instance, Bricheno and Thornton; 2007). Relatives with high education may impact the educational attainments of children in at least two ways. First, by providing role models, they may increase educational aspirations of children, possibly leading to higher educational attainment. Second, they may affect parental decisions regarding children's education by shaping parents' opinions toward children's education. Our survey includes a question that asks the respondents the educational attainment of the relative with highest education level when they were between the ages of 7 and 12. For each region, we compute the mean of this 
variable across observations in that region. The fifh row of Table 10 reports how intergenerational persistence in education changes with years of schooling of the most highly educated relative across regions in Turkey. We find that intergenerational mobility is higher for daughters in regions where the years of schooling of the relative with highest education is higher. Interestingly, we find no such effect of this variable on mobility of males. One explanation for this differential across genders may be as follows. In less developed regions, where gender culture is less favorable toward female education, highly educated relatives may encourage parental investment in daughters' education among low educated parents, and hence, decrease intergenerational persistence of education for females.

Education mobility and inequality We also correlate intergenerational mobility in education with educational inequality across development regions. Our measure of educational inequality is the Gini index of parental years of schooling in each development region. We regress the intergenerational regression coefficients estimated in Section 5.3 on our educational inequality variable. The sixth row of Table 10 reports the results. We find that the Gini coefficient of parental years of schooling is positively associated with intergenerational persistence for all six specifications, and these relationships are significant except for the Father-daughter specification. This provides evidence for the existence of a Great Gatsby curve in education: those regions in which education mobility is lower also feature higher crosssectional education inequality. This finding is in line with the evidence presented by Krueger (2012) and Corak (2013) who show that countries with more inequality as measured by income Gini coefficients also display less intergenerational income mobility. Guell at al. (2015) shows a similar result in the context of Italian provinces.

Table 10 [about here]

\subsection{Absolute Mobility and Development}


In this section, we investigate the relationship between development and bottom-to-top and bottom-to-bottom probabilities using the nonparametric approach. Figure 4 presents the results for bottom-to-top probability. We observe that probability of going from the bottom of the education distribution to its top increases significantly with socioeconomic development. For instance, the top left panel of the figure shows that only $5 \%$ of the children whose fathers are at the lowest education category receive a college/university degree in the least developed region whereas the same number is $15 \%$ in the most developed region. Children born into lowest education parents have three times more chance of going to college in the most vs. least developed regions. Figure 5 presents how the probability of being stuck at the bottom of the education distribution (bottom-to-bottom probability) changes with economic development. The probability of remaining at the bottom is much higher in less developed regions. For example, the top left panel in Figure 5 indicates that children who grew up in the provinces that are in least developed region and whose fathers have primary school education or less have a $90 \%$ chance of having primary school education or less whereas the probability of getting stuck at the bottom of the education distribution is $60 \%$ in the most developed region. ${ }^{35}$

Figure 4 [about here]

Figure 5 [about here]

\footnotetext{
35 We investigate the relationship between development and bottom-to-top and bottom-to-bottom probabilities using a parametric approach as well. To investigate the effect of development on bottom-to-top probability, we restrict the sample to observations in which parents have less than primary school education and estimate:
}

$$
Y_{i}=\alpha+\gamma \operatorname{DevInd}_{i}+\varepsilon_{i}
$$

where $Y_{i}$ is a variable that takes the value 1 if the children's education level is college or university and 0 otherwise. We estimate equation (6) separately for Father-all, Mother-all, Father-son, Mother-son, Fatherdaughter, and Mother-daughter pairs. We do not present the results of these estimations in the current paper for the sake of brevity, but instead briefly discuss them in this footnote. We find that the estimates of $\gamma$ are highly significant and positive in all pairs, showing that the probability of reaching the top of the education distribution for children coming from families where the parents are at the bottom of the education distribution is higher in regions with higher level of economic development. We also investigate how bottom-to-bottom probability changes with economic development using specification (6) for the same restricted sample with $Y_{i}$ taking the value 1 if the children have less than primary school education and 0 otherwise. The results show that the bottom-tobottom probability is lower in regions with higher economic development. The results of the bottom-to-top and bottom-to-bottom estimations are available upon request. 


\section{Conclusion}

This paper contributes to the literature on intergenerational mobility in two ways. First, we estimate the degree of education mobility in Turkey. We find that the level of mobility in Turkey at the national level is significantly lower than that in the United States and European countries. We also analyze three-generation mobility and find no evidence for a direct effect of grandparents' educational attainments on children's educational attainments.

Our second and main contribution is to establish a relationship between economic development and intergenerational mobility. Both our parametric and nonparametric analyses show that educational outcomes of daughters who grow up in more developed regions depend less on their parents' educational outcomes. Interestingly, we do not find strong evidence for a similar relationship between development and mobility for males. Moreover, we find that the positive association between the development level of place of residence and intergenerational mobility is significantly stronger when we define place of residence as the place of residence during the ages of 0-6 and 7-12 rather than later years.

Finally, we compute correlations of intergenerational education mobility estimates with regional characteristics. While this exercise cannot determine causal mechanisms, it provides important insights regarding the importance of several correlates for intergenerational mobility. We find that in regions with higher school availability and more favorable gender culture toward women intergenerational mobility is higher for daughters. We find no significant association of either school availability or gender culture with mobility of males. Our results also point to a positive correlation between educational inequality in a region and intergenerational mobility in education. Further analysis of the relationship between development and intergenerational mobility may shed light on the underlying causal mechanisms that lead to the correlations we report in this paper between regional characteristics and intergenerational education mobility. 


\section{References}

BEHRMAN, J. R., Taubman P., Intergenerational Earnings Mobility in the United States: Some Estimates and a Test of Becker's Intergenerational Endowments Model, Review of Economics and Statistics, 67, 144-151, (1985).

BLACK S. E., Devereux P. J., Recent Developments in Intergenerational Mobility, Handbook of Labor Economics, ed: Ashenfelter O., Card D., Elsevier, 1487-1541, (2011).

BRAUN S., Stuhler J., The Transmission of Inequality Across Generations: Testing Recent Theories with Evidence from Germany, Economic Journal, forthcoming.

BRICHENO, P., Thornton, J., Role model, hero or champion? Children's views concerning role models, Educational Research, 49 (4), 383-396, (2007).

CHIANG, Y. and H. Park, Do grandparents matter? A multigenerational perspective on educational attainment in Taiwan, Social Science Research 51, 163-173, (2015).

CORAK, M., Income Inequality, Equality of Opportunity, and Intergenerational Mobility. Journal of Economic Perspectives, 27, no. 3, 79-102, (2013).

CHETTY R., Hendren N., Kline P., Saez E., Where is the Land of Opportunity? The Geography of Intergenerational Mobility in the United States, Quarterly Journal of Economics 129 (3), 1553-1623, (2014).

CHETTY R. and Hendren N., The Effects of Neighborhoods on Intergenerational Mobility I: Childhood Exposure Effects, National Bureau of Economic Research Working Paper No. 23001, (2016). 
DICKENS, W.T., Error components in grouped data: is it ever worth weighting?

Rev.Econ. Stat. 72 (2), 328-333 (1990).

ELANGO, S., Garcia, J., Heckman, J., and Hojman, A., Early Childhood Education, in Economics of Means-Tested Transfer Programs in the United States, 2, 235-297, National Bureau of Economic Research, Inc, (2015).

GUELL M., Pellizzari M., Pica G., Rodriguez Mora J. V., Correlating Social Mobility and Economic Outcomes, Working paper, (2015).

HERTZ T., Jayasundera T., Piraino P., Selcuk S., Smith N., Verashchagina A., The inheritance of educational inequality: International comparisons and fifty-year trends, The B.E. Journal of Economic Analysis \& Policy, 7 (2), Article 10, (2007).

JAEGER, M. The Extended Family and Children's Educational Success, American Sociological Review 77(6) 903-922, (2012).

KALKINMA BAKANLIĞI (KB), İllerin ve Bölgelerin Sosyo-ekonomik Gelişmişlik Sıralaması Araştırması, Ankara, (2013).

KERR S. P., Lucas, R. E. B., Intergenerational Income Immobility in Finland:

Contrasting Roles for Parental Earnings and Family Income, Journal of Population Economics, (26), 1057-1094, (2013).

KIRDAR M., Explaining Ethnic Disparities in School Enrollment in Turkey, Economic Development and Cultural Change 57(2) pp. 297-333 (2009).

KING, E. M. and M. A. Hill, Women's Education in Developing Countries: Barriers, Benefits, and Policies, John Hopkins University Press, USA, (1993). 
KINGDON, Geeta Gandhi, "Where Has All the Bias Gone? Detecting Gender Bias in the Intrahousehold Allocation of Educational Expenditure," Economic Development and Cultural Change 53(2): 409-51, (2005).

KRUEGER, A., "The Rise and Consequences of Inequality in the United States," Speech at the Center for American Progress, Washington, DC, January 12, 2012.

KORKMAZ A., Sosyal Hareketlilik: Eğitim ve Mesleğin Sosyal Hareketliliğe Etkisi, Sosyoloji Konferansları, 30, İstanbul, (2005).

LINDAHL, M., Palme M., Massih S. S., Sjögren A., Long-Term Intergenerational Persistence of Human Capital: An Empirical Analysis of Four Generations, Journal of Human Resources, 50(1), 1-33, (2015).

ÖZDURAL S., Intergenerational Mobility: A comperative study between Turkey and the United States, Economics Letters, 43, 221-230, (1993).

RIDGE, J. M., Three Generations, Mobility in Britain Reconsidered, ed: J. M. Ridge, Oxford, Clarendon Press, (1974).

SACERDOTE, B., The Nature and Nurture of Economic Outcomes", American Economic Review, American Economic Association, 92 (2), 344-348, (2002).

SOLON G. Intergenerational Mobility in the Labor Market, in Handbook of Labor Economics, Volume 3A. Orley C. Ashenfelter and David Card, eds. Amsterdam: North-Holland, pp. 1761-800, (1999).

SOLON G., Haider, S.J., Wooldridge, J., What are we weighting for? NBER working paper 18859, (2013). 
SOLON G., What Do We Know So Far about Multigenerational Mobility? NBER Working Paper No: 21053, (2015).

TANSEL A., Determinants of school attainment of boys and girls in Turkey:

individual, household and community factors, Economics of Education Review, 21, 455-470, (2002).

TANSEL, A., Intergenerational Educational Mobility in Turkey, IZA DP No. 9590. (2015).

UYSAL-KOLAŞİN G., Yontar M. Y., Babanın Eğitimi Çocuğun Ücretini Etkiliyor, Betam Araştıma Notu 12/128, 1-6, (2012).

WARREN JR and RM Hauser. Social stratification across three generations: New evidence from the Wisconsin longitudinal study, American Sociological Review, 62 (4), 561-572, (1997).

ZENG, Z. and Y. Xie, The Effects of Grandparents on Children's Schooling: Evidence from Rural China, Demography, 51 (2), 599-617, (2014). 
Figure 1: Mean child years of schooling by father's years of schooling

Panel A: Years of schooling

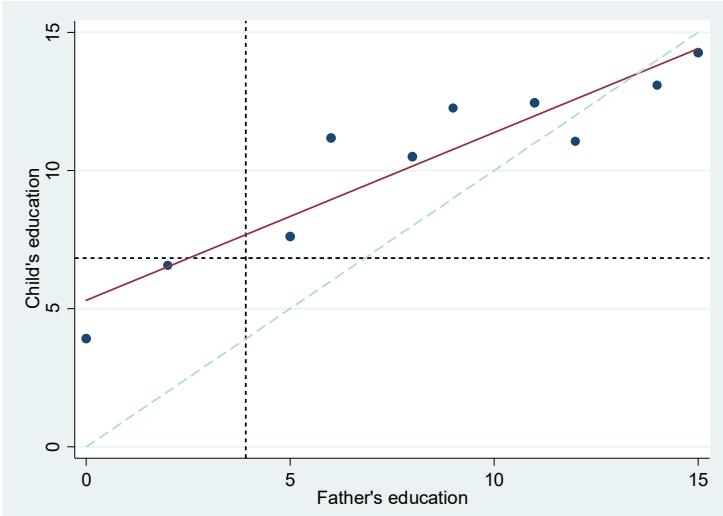

Panel B: Adjusted years of schooling

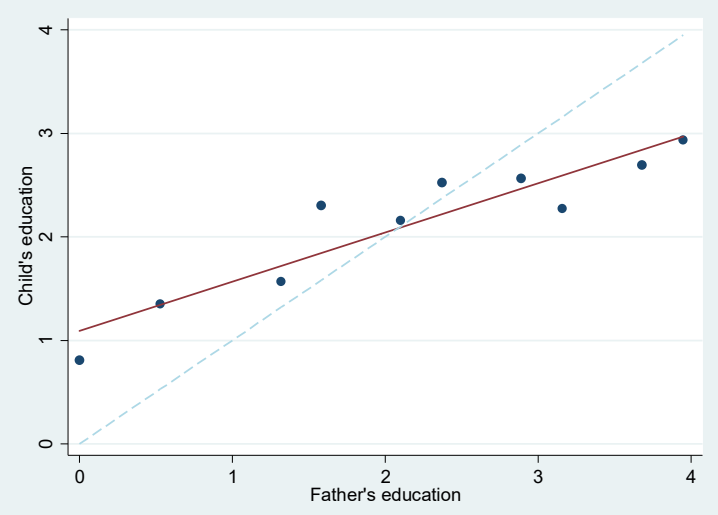

Notes: Panel A plots mean years of schooling of children as a function of fathers' years of schooling. Panel B presents the same plot taking adjusted years of schooling as education variable. 


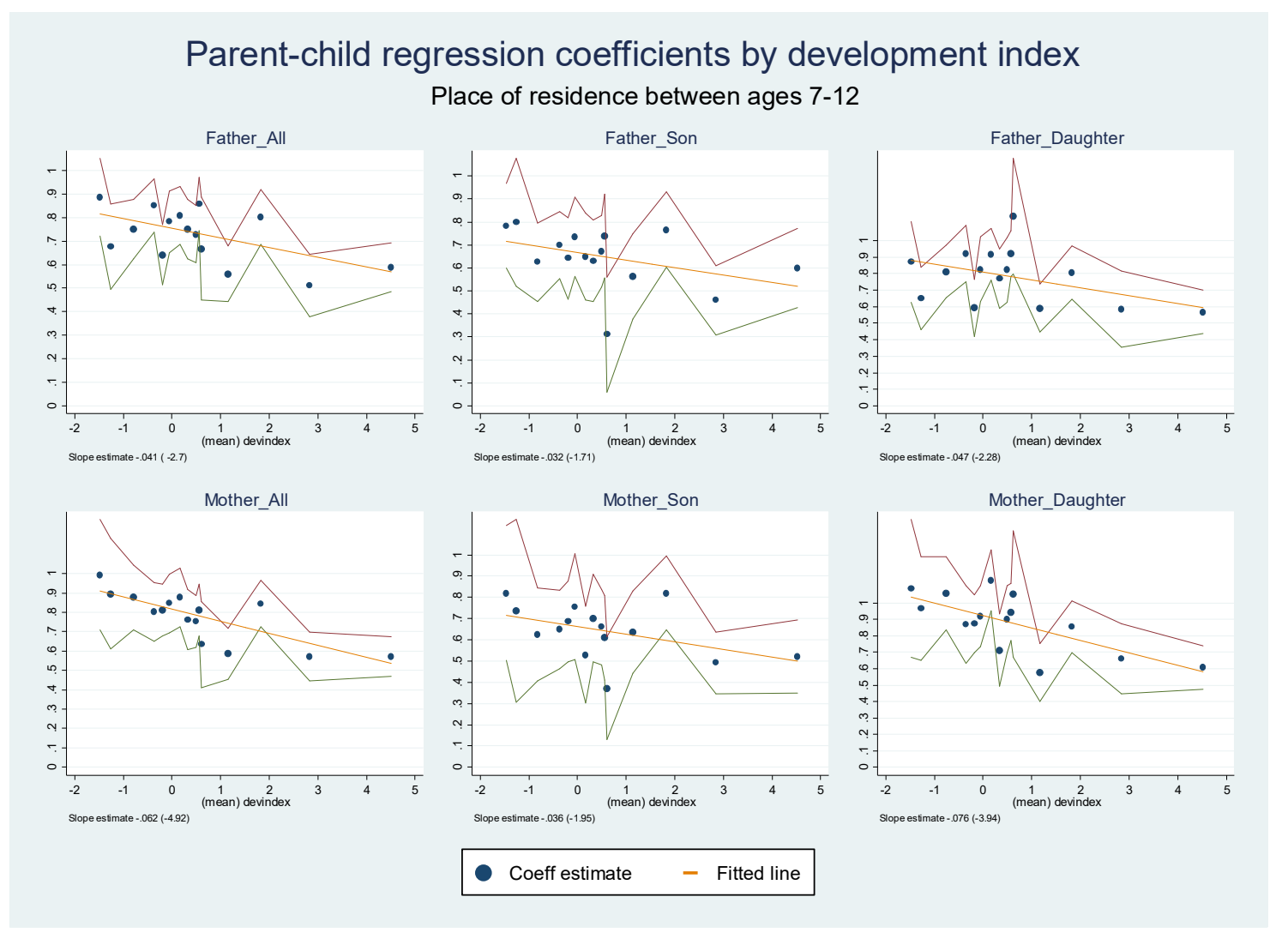

Notes: The top left panel presents estimates of the regression coefficient of fathers' years of schooling in the regression where children's years of schooling is the dependent variable and fathers' years of schooling is the independent variable for all 15 development regions. Each blue dot represents a development region. The horizontal axis indicates the mean development score of the region whereas the vertical axis indicates the regression coefficient of fathers' years of schooling estimated for that region. The red-green band provides $95 \%$ confidence for the corresponding estimate of the regression coefficient. The orange line provides a linear fit to the estimated regression coefficients. The number below each graph refers to the estimated slope of the fitted line. The number in parenthesis is the associated t-stat value. The bottom left panel displays the same graph taking mothers' years of schooling as the independent variable in the intergenerational education regression. The top middle and bottom middle panels display intergenerational mobility estimates in all 15 regions for the male subsample while the top right and bottom right panels display regional mobility estimates for the female subsample. 
Figure 3: Heat Map of Intergenerational Mobility in Turkey

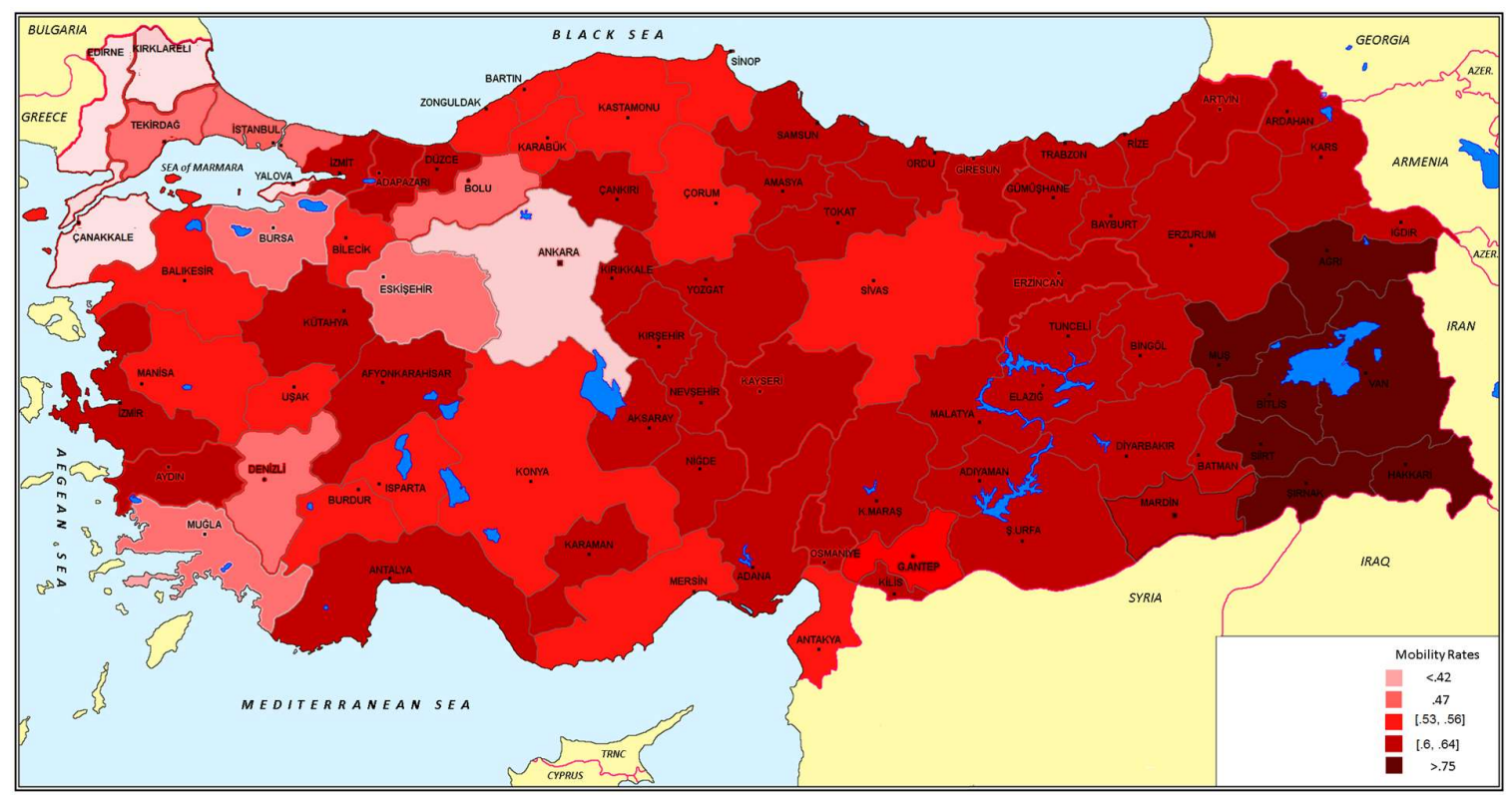

Notes: This figure provides a heat map of intergenerational mobility in Turkey. For each one of our 15

development regions, we estimate the correlation between the average years of schooling of parents and children's years of schooling in that region. Lighter colors represent lower correlation values. All provinces within a development region have the same color. The sample used to compute correlations is restricted to include individuals who are between the ages of 20 and 69 . 
Figure 4: Bottom-to-Top Probability by Level of Development

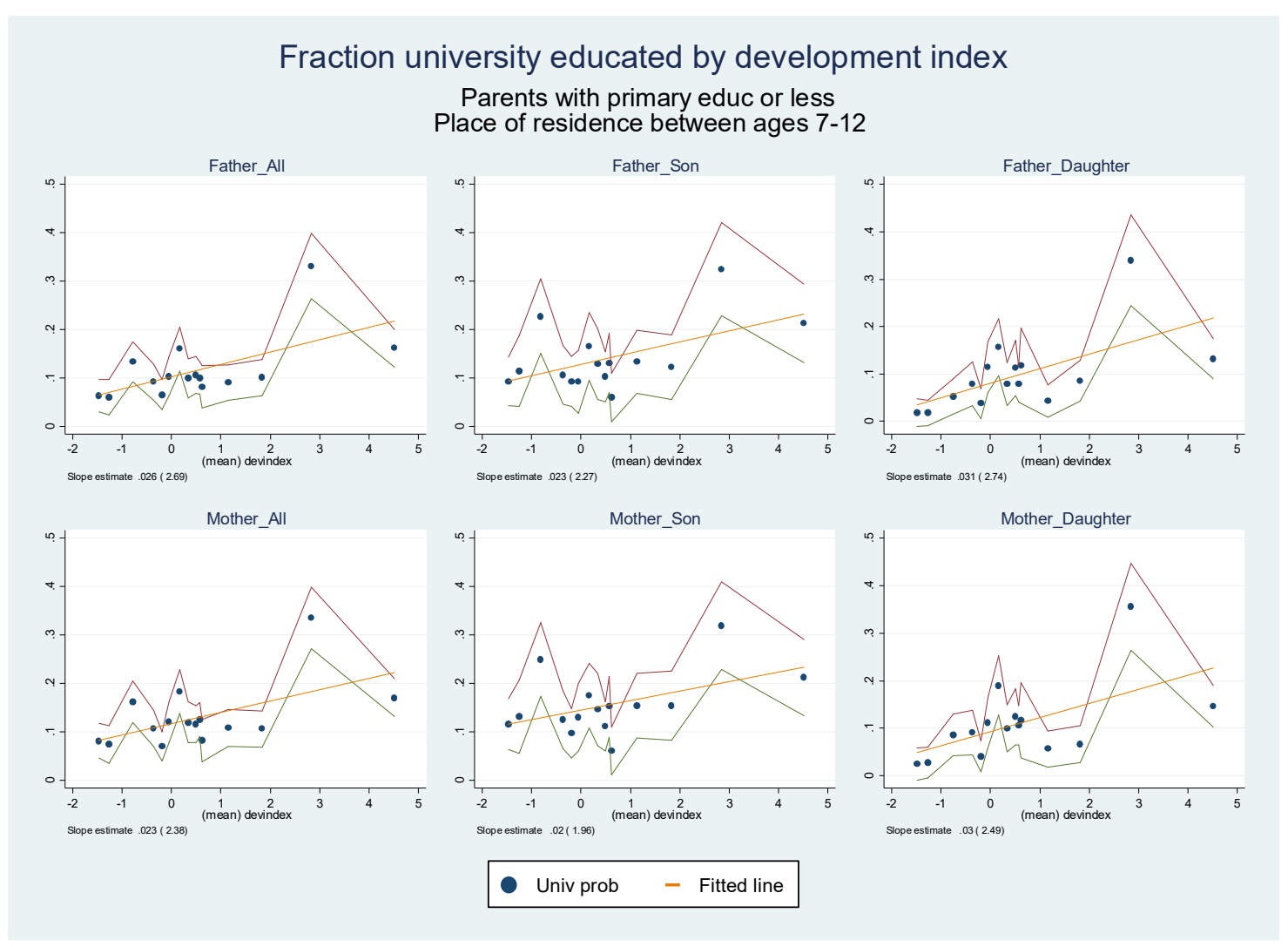

Notes: The top left panel presents estimates of the bottom-to-top probability - the probability that a child receives college or university education when the father has less than primary school education - for all 15 development regions. Each blue dot represents a development region. The horizontal axis indicates the mean development score of the region whereas the vertical axis indicates the bottom-to-top probability estimated for that region. The redgreen band provides $95 \%$ confidence for the corresponding estimate. The orange line provides a linear fit to the estimated bottom-to-top probabilities. The number below each graph refers to the estimated slope of the fitted line. The number in parenthesis is the associated t-stat value. The bottom left panel displays the same probability for children whose mothers have less than primary school education. The top middle and bottom middle panels display bottom-to-top probabilities in all 15 regions for the male subsample while the top right and bottom right panels display regional bomttom-to-top probability estimates for the female subsample. 
Figure 5: Bottom-to-Bottom Probability by Level of Development

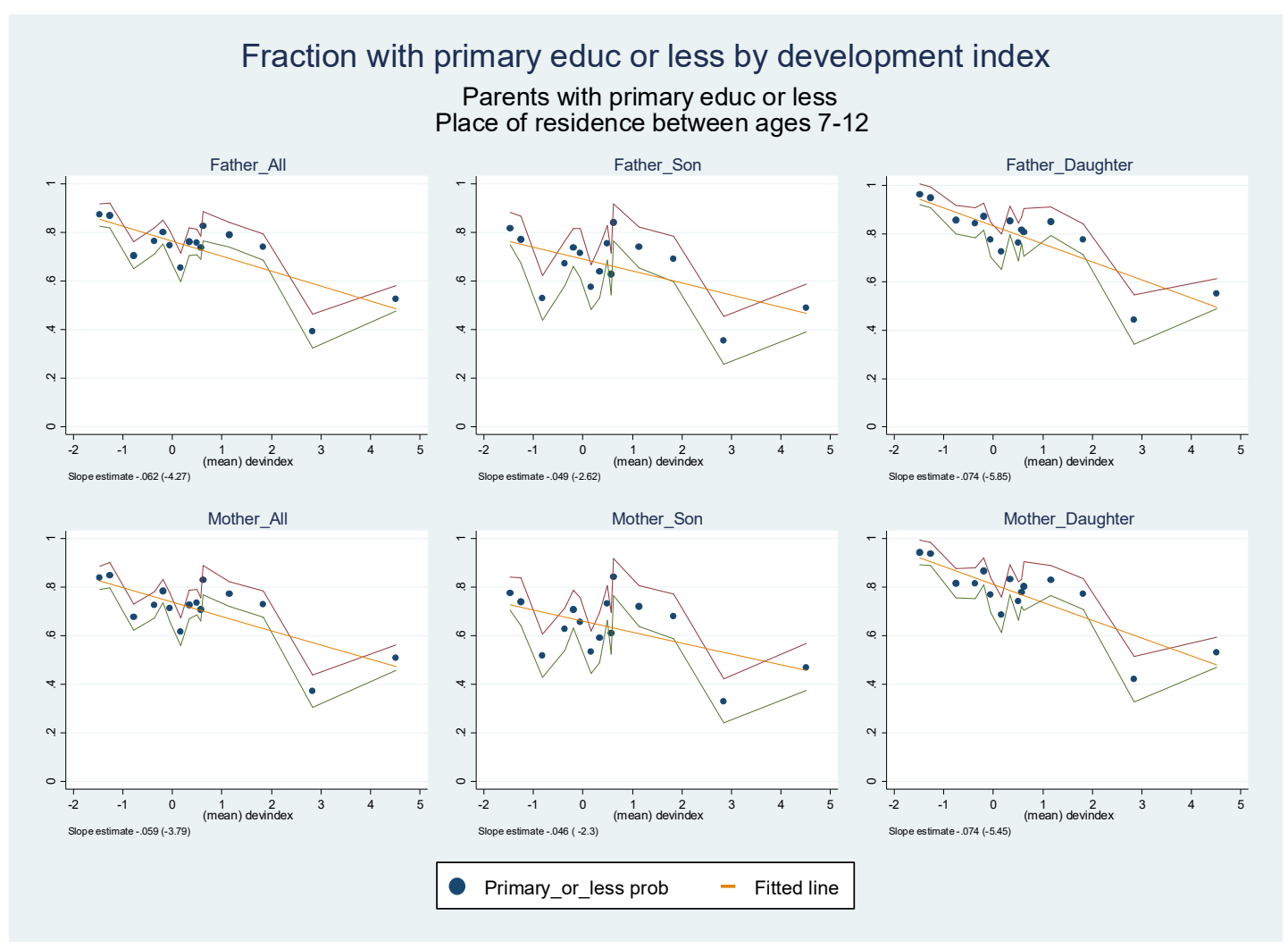

Notes: The top left panel presents estimates of the bottom-to-bottom probability - the probability that a child receives less than primary school education when the father has less than primary school education - for all 15 development regions. Each blue dot represents a development region. The horizontal axis indicates the mean development score of the region whereas the vertical axis indicates the bottom-to-bottom probability estimated for that region. The red-green band provides $95 \%$ confidence for the corresponding estimate. The orange line provides a linear fit to the estimated bottom-to-bottom probabilities. The number below each graph refers to the estimated slope of the fitted line. The number in parenthesis is the associated t-stat value. The bottom left panel displays the same prabibility for children whose mothers have less than primary school education. The top middle and bottom middle panels display bottom-to-bottom probabilities in all 15 regions for the male subsample while the top right and bottom right panels display regional bomttom-to-bottom probability estimates for the female subsample. 
Table 1: Descriptive Statistics

\begin{tabular}{|c|c|c|c|c|c|}
\hline & Obs & Mean & Std. Dev. & Min & Max \\
\hline Age & 3500 & 45.4 & 14.62 & 25 & 87 \\
\hline Male & 3500 & 0.49 & 0.5 & 0 & 1 \\
\hline Children's education & 3500 & 6.84 & 4.69 & 0 & 21 \\
\hline Father's education & 3420 & 3.91 & 3.6 & 0 & 21 \\
\hline Mother's education & 3405 & 2.65 & 3.25 & 0 & 21 \\
\hline & $\begin{array}{l}\text { Less than } \\
\text { pirmary }\end{array}$ & $\begin{array}{c}\text { Primary/lower } \\
\text { sec sch }\end{array}$ & HS & \multicolumn{2}{|c|}{ College or univ } \\
\hline Male children & 8.7 & 55.7 & 19.1 & \multicolumn{2}{|c|}{16.5} \\
\hline Female children & 29.2 & 47.8 & 11.6 & \multicolumn{2}{|c|}{11.3} \\
\hline Fathers & 38.5 & 53.4 & 5.8 & \multicolumn{2}{|c|}{2.3} \\
\hline Mothers & 56.0 & 39.7 & 3.3 & \multicolumn{2}{|c|}{1.1} \\
\hline
\end{tabular}

Notes: This table provides descriptive statistics for the main sample, which includes respondents who are age 25 or older. Panel A reports basic statistics for various demographic and educational characteristics. Panel B of Table 1 provides further information on educational attainment by generation. 
Table 2 - Spatial Distribution in the Survey vs. HLFS 2013

\begin{tabular}{clcc}
\hline NUTS1 Region code & NUTS1 Region name & Fraction in our sample & Fraction in HLFS 2013 \\
\hline & & & \\
TR1 & ístanbul & 17.21 & 18.23 \\
TR2 & Batı Marmara & 6.71 & 5.12 \\
TR3 & Ege & 9.94 & 14.33 \\
TR4 & Doğu Marmara & 11.49 & 10.49 \\
TR5 & Batı Anadolu & 10.44 & 9.78 \\
TR6 & Akdeniz & 12.81 & 12.76 \\
TR7 & Orta Anadolu & 4.90 & 4.96 \\
TR8 & Batı Karadeniz & 5.68 & 6.31 \\
TR9 & Doğu Karadeniz & 3.14 & 3.72 \\
TRA & Kuzeydoğu Anadolu & 2.61 & 2.29 \\
TRB & Ortadoğu Anadolu & 5.15 & 4.00 \\
TRC & Güneydoğu Anadolu & 9.91 & 8.00 \\
\hline
\end{tabular}

Notes: This table provides a comparison of the geographical distribution of our sample across Turkey to the geographical distribution in the Household Labor Force Survey (HLFS) conducted by TUIK. TUIK partitions Turkey into 12 broad regions called NUTS1 regions. Column entitled "Fraction in our sample" reports the fractions of people living in each region in our survey while the column entitled "Fraction in HLFS 2013" reports corresponding fractions in HLFS 2013. 
Table 3: Education Mobility at the National Level

\begin{tabular}{|c|c|c|c|c|c|c|}
\hline \multirow[b]{2}{*}{ VARIABLES } & \multicolumn{3}{|c|}{ Regression coefficient } & \multicolumn{3}{|c|}{ Correlation coefficient } \\
\hline & (1) & $(2)$ & (3) & (4) & (5) & (6) \\
\hline \multirow[t]{2}{*}{ Father's education } & $0.734 * * *$ & & $0.493^{* * *}$ & $0.564^{* * *}$ & & $0.379 * * *$ \\
\hline & {$[0.018]$} & & {$[0.026]$} & {$[0.014]$} & & {$[0.020]$} \\
\hline \multirow[t]{2}{*}{ Mother's education } & & $0.767 * * *$ & $0.364 * * *$ & & $0.532 * * *$ & $0.252 * * *$ \\
\hline & & {$[0.021]$} & [0.029] & & {$[0.015]$} & {$[0.020]$} \\
\hline Observations & 3,420 & 3,405 & 3,388 & 3,420 & 3,405 & 3,388 \\
\hline R-squared & 0.319 & 0.283 & 0.348 & 0.319 & 0.283 & 0.348 \\
\hline
\end{tabular}

Notes: Column (1) reports the regression coefficient associated with fathers' years of schooling in the regression where we regress children's years of schooling on fathers' years of schooling using our main sample. Column (2) reports results for the regression where mothers' years of schooling is the independent variable. Column (3) reports results for the regression where both parents' years of schooling are included as independent variables. Columns (4)-(6) repeat the exercises in columns (1)-(3) using adjusted years of schooling as the education measure. Standard errors in brackets $* * * \mathrm{p}<0.01, * * \mathrm{p}<0.05, * \mathrm{p}<0.1$ 
Table 4: Three-generation Education Mobility

\begin{tabular}{|c|c|c|c|c|c|c|c|c|}
\hline VARIABLES & (1) & (2) & (3) & (4) & (5) & (6) & (7) & (8) \\
\hline Father's education & $\begin{array}{c}0.509 * * * \\
{[0.026]}\end{array}$ & & $\begin{array}{c}0.488^{* * *} \\
{[0.032]}\end{array}$ & $\begin{array}{c}0.426^{* * *} \\
{[0.038]}\end{array}$ & & & & $\begin{array}{c}0.410^{* * *} \\
{[0.037]}\end{array}$ \\
\hline Paternal grandfather's education & & $\begin{array}{c}0.350 * * * \\
{[0.064]}\end{array}$ & $\begin{array}{c}0.076 \\
{[0.056]}\end{array}$ & $\begin{array}{c}0.037 \\
{[0.055]}\end{array}$ & & & & \\
\hline Mother's education & & & & $\begin{array}{c}0.147^{* * *} \\
{[0.048]}\end{array}$ & $\begin{array}{c}0.465^{* * *} \\
{[0.037]}\end{array}$ & & $\begin{array}{c}0.436 * * * \\
{[0.046]}\end{array}$ & $\begin{array}{c}0.190^{* * *} \\
{[0.046]}\end{array}$ \\
\hline Maternal grandfather's education & & & & & & $\begin{array}{c}0.338^{* * *} \\
{[0.053]}\end{array}$ & $\begin{array}{l}0.115^{*} \\
{[0.058]}\end{array}$ & $\begin{array}{c}0.025 \\
{[0.047]}\end{array}$ \\
\hline Observations & 2,079 & 1,884 & 1,871 & 1,868 & 2,096 & 1,926 & 1,926 & 1,903 \\
\hline R-squared & 0.233 & 0.057 & 0.237 & 0.246 & 0.147 & 0.055 & 0.161 & 0.261 \\
\hline
\end{tabular}

Notes: Column (1) reports the results of a regression for the subsample in which respondents are male and have at least one child of at least 25 years of age. Father's education refers to years of schooling of the respondent while children years of schooling refers to that of the randomly selected child of at least 25 years of age. Column (2) reports results of the regression where we regress children's years of schooling on paternal grandfathers' years of schooling. Paternal grandfather refers to respondent's father. Column (3) reports results for the regression where both father's and paternal grandparent's years of schooling are included as independent variables. Columns (4)-(6) repeat the exercises in columns (1)-(3) for the subsample in which respondents are female and have at least one child of at least 25 years of age. All standard errors are clustered at the family level since our sample contains different observations from same families. Standard errors in brackets $* * * p<0.01,{ }^{* *} \mathrm{p}<0.05, * \mathrm{p}<0.1$ 
Table 5: Transition matrices

\begin{tabular}{|c|c|c|c|c|}
\hline \multirow[b]{2}{*}{ Father's education } & \multicolumn{4}{|c|}{ Child's education } \\
\hline & $\begin{array}{c}\text { Less than } \\
\text { primary }\end{array}$ & $\begin{array}{c}\text { Primary/ } \\
\text { lowersec }\end{array}$ & $\mathrm{HS}$ & $\begin{array}{c}\text { College or } \\
\text { univ }\end{array}$ \\
\hline Less than primary & 38.35 & 52.55 & 5.66 & 3.44 \\
\hline Primary/lower sec & 6.85 & 57.45 & 20.56 & 15.14 \\
\hline HS & 3.51 & 14.24 & 32.1 & 50.15 \\
\hline \multirow[t]{2}{*}{ College or univ } & 0 & 7.31 & 21.23 & 71.47 \\
\hline & \multicolumn{4}{|c|}{ Child's education } \\
\hline Mother's education & $\begin{array}{l}\text { Less than } \\
\text { primary }\end{array}$ & $\begin{array}{l}\text { Primary/ } \\
\text { lowersec }\end{array}$ & $\mathrm{HS}$ & $\begin{array}{c}\text { College or } \\
\text { univ }\end{array}$ \\
\hline Less than primary & 31.27 & 54.98 & 7.78 & 5.97 \\
\hline Primary/lower sec & 3.68 & 52.15 & 25.14 & 19.04 \\
\hline HS & 0 & 5.84 & 27.81 & 66.36 \\
\hline College or univ & 0 & 0 & 16 & 84 \\
\hline
\end{tabular}

Notes: This table presents father-child and mother child transition matrices in the top and bottom panels, respectively. "Less than primary education" category includes those who attended primary school but did not obtain a diploma, those who never attended formal school but are literate, and those who are illiterate.

"Primary/lower sec" category includes individuals who have a primary or a lower secondary school degree. "HS" group refers to people with a high school diploma and "College or univ" category includes individuals with at least a two-year college degree. 
Table 6: Intergenerational Education Mobility by Gender

\begin{tabular}{lccc}
\hline VARIABLES & $(1)$ & $(2)$ & $(3)$ \\
\hline & & & \\
Father's education & $0.660^{* * *}$ & & $0.519^{* * *}$ \\
& {$[0.025]$} & & {$[0.038]$} \\
Father's education*Female & $0.135^{* * *}$ & & -0.033 \\
& {$[0.035]$} & & {$[0.051]$} \\
Mother's education & & $0.638^{* * *}$ & $0.202^{* * *}$ \\
& & {$[0.028]$} & {$[0.042]$} \\
Mother's education*Female & & $0.242^{* * *}$ & $0.295^{* * *}$ \\
& & {$[0.040]$} & {$[0.057]$} \\
Male & $2.505^{* * *}$ & $2.571^{* * *}$ & $2.586^{* * *}$ \\
& {$[0.188]$} & {$[0.170]$} & {$[0.184]$} \\
& & & \\
Observations & 3,420 & 3,405 & 3,388 \\
R-squared & 0.367 & 0.332 & 0.399 \\
\hline
\end{tabular}

Notes: Column (1) reports results of the regression equation $S_{1 i}=\alpha+\beta_{0} S_{0 i}+\beta_{1} S_{0 i}{ }^{*} G_{i}+\beta_{2} E_{i}+e_{i}$, where $S_{1}$ and $S_{0}$ represent individual's and father's years of schooling, $G$ is a dummy variable that takes value 1 if the individual is female and 0 otherwise, and $E$ is a dummy variable that takes the value 1 if the individual is male and 0 if female. Column (2) conducts the same regression for the case in which parental input is mother's years of schooling. Column (3) reports the results of the same exercise this time including both father's and mother's years of schooling as parental inputs. Standard errors in brackets ${ }^{* * *} \mathrm{p}<0.01,{ }^{* *} \mathrm{p}<0.05,{ }^{*} \mathrm{p}<0.1$. 
Table 7 - Relationship between Mobility and Development, Parametric Estimates

\begin{tabular}{|c|c|c|c|c|c|c|}
\hline VARIABLES & $\begin{array}{l}\text { Father-all } \\
\text { (1) }\end{array}$ & $\begin{array}{c}\text { Father-son } \\
\text { (2) }\end{array}$ & $\begin{array}{c}\text { Father-daughter } \\
\text { (3) }\end{array}$ & $\begin{array}{l}\text { Mother-all } \\
\text { (4) }\end{array}$ & $\begin{array}{c}\text { Mother-son } \\
\text { (5) }\end{array}$ & $\begin{array}{c}\text { Mother-daughter } \\
\text { (6) }\end{array}$ \\
\hline devindex & $\begin{array}{c}0.485^{* * *} \\
{[0.121]}\end{array}$ & $\begin{array}{c}0.225 \\
{[0.169]}\end{array}$ & $\begin{array}{c}0.781 * * * \\
{[0.095]}\end{array}$ & $\begin{array}{c}0.451 * * * \\
{[0.103]}\end{array}$ & $\begin{array}{c}0.186 \\
{[0.153]}\end{array}$ & $\begin{array}{c}0.750 * * * \\
{[0.108]}\end{array}$ \\
\hline Parent's education & $\begin{array}{c}0.769 * * * \\
{[0.023]}\end{array}$ & $\begin{array}{c}0.683^{* * *} \\
{[0.028]}\end{array}$ & $\begin{array}{c}0.833^{* * *} \\
{[0.034]}\end{array}$ & $\begin{array}{c}0.825^{* * *} \\
{[0.029]}\end{array}$ & $\begin{array}{c}0.662 * * * \\
{[0.029]}\end{array}$ & $\begin{array}{c}0.961 * * * \\
{[0.043]}\end{array}$ \\
\hline Parent's education* devindex & $\begin{array}{c}-0.036 * * * \\
{[0.011]}\end{array}$ & $\begin{array}{l}-0.015 \\
{[0.014]}\end{array}$ & $\begin{array}{c}-0.056 * * * \\
{[0.013]}\end{array}$ & $\begin{array}{c}-0.051 * * * \\
{[0.012]}\end{array}$ & $\begin{array}{l}-0.009 \\
{[0.018]}\end{array}$ & $\begin{array}{c}-0.091^{* * *} \\
{[0.016]}\end{array}$ \\
\hline Constant & $\begin{array}{c}4.033^{* * *} \\
{[0.154]}\end{array}$ & $\begin{array}{c}5.426^{* * *} \\
{[0.208]}\end{array}$ & $\begin{array}{c}2.709 * * * \\
{[0.148]}\end{array}$ & $\begin{array}{c}4.901 * * * \\
{[0.145]}\end{array}$ & $\begin{array}{c}6.339 * * * \\
{[0.201]}\end{array}$ & $\begin{array}{c}3.552 * * * \\
{[0.162]}\end{array}$ \\
\hline Observations & 4,154 & 1,854 & 2,300 & 4,144 & 1,846 & 2,298 \\
\hline
\end{tabular}

Notes: This table reports the results of the regression equation $\mathrm{S}_{1 \mathrm{i}}=\alpha+\beta_{0} S_{0 i}+\beta_{1}\left(S_{0 i} * \operatorname{DevInd}_{i}\right)+\gamma$ DevInd $_{i}+\varepsilon_{i}$ where $\operatorname{DevInd}_{i}$ is the development index score for individual $i$ 's place of residence between ages of 7 and 12 . The first column named Father-all refers to the regression specification in which parental education variable is fathers' years of schooling and the sample includes all observations in our main sample. The next five columns are defined similarly. Standard errors are clustered at the province level. Standard errors in brackets $* * * \mathrm{p}<0.01, * * \mathrm{p}<0.05, *$ $\mathrm{p}<0.1$. 
Table 8 - Sensitivity to Various Definitions of Area of Residence

\begin{tabular}{lcccccccc}
\hline & \multicolumn{9}{c}{ Father-daughter } & \multicolumn{5}{c}{ Mother-daughter } \\
\hline \multirow{3}{*}{ VARIABLES } & Current res. & $13-18$ & $7-12$ & $0-6$ & Current res. & $13-18$ & $7-12$ & $0-6$ \\
\hline & $(1)$ & $(2)$ & $(3)$ & $(4)$ & $(5)$ & $(6)$ & $(7)$ & $(8)$ \\
\hline \multirow{3}{*}{ Devindex } & & & & & & & & \\
& $0.364^{* * *}$ & $0.661^{* * *}$ & $0.781^{* * *}$ & $0.839^{* * *}$ & $0.337^{* *}$ & $0.651^{* * *}$ & $0.750^{* * *}$ & $0.756^{* * *}$ \\
Parent's education & {$[0.129]$} & {$[0.100]$} & {$[0.095]$} & {$[0.101]$} & {$[0.128]$} & {$[0.094]$} & {$[0.108]$} & {$[0.120]$} \\
& $0.877^{* * *}$ & $0.827^{* * *}$ & $0.833^{* * *}$ & $0.828^{* * *}$ & $1.005^{* * *}$ & $0.963^{* * *}$ & $0.961^{* * *}$ & $0.945^{* * *}$ \\
Parent's education*devindex & {$[0.038]$} & {$[0.035]$} & {$[0.034]$} & {$[0.034]$} & {$[0.054]$} & {$[0.045]$} & {$[0.043]$} & {$[0.042]$} \\
& $-0.029^{* *}$ & $-0.033^{* *}$ & $-0.056^{* * *}$ & $-0.058^{* * *}$ & $-0.051^{* * *}$ & $-0.070^{* * *}$ & $-0.091^{* * *}$ & $-0.084^{* * *}$ \\
Constant & {$[0.015]$} & {$[0.016]$} & {$[0.013]$} & {$[0.015]$} & {$[0.018]$} & {$[0.019]$} & {$[0.016]$} & {$[0.019]$} \\
& $2.518^{* * *}$ & $2.628^{* * *}$ & $2.709^{* * *}$ & $2.743^{* * *}$ & $3.416^{* * *}$ & $3.455^{* * *}$ & $3.552^{* * *}$ & $3.602^{* * *}$ \\
& {$[0.197]$} & {$[0.157]$} & {$[0.148]$} & {$[0.151]$} & {$[0.229]$} & {$[0.165]$} & {$[0.162]$} & {$[0.163]$} \\
Observations & & & & & & & & \\
R-squared & 2,300 & 2,297 & 2,300 & 2,291 & 2,298 & 2,295 & 2,298 & 2,289 \\
& 0.404 & 0.422 & 0.423 & 0.423 & 0.384 & 0.404 & 0.403 & 0.400 \\
\hline
\end{tabular}

Notes: Column (1) reports the estimates of the regression equation $\mathrm{S}_{1 \mathrm{i}}=\alpha+\beta_{0} S_{0 i}+\beta_{1}\left(S_{0 i}{ }^{*}\right.$ DevInd $\left._{i}\right)+\gamma$ DevInd $_{i}+\varepsilon_{i}$ for the female subsample where parent's education refers to father's years of schooling and $\operatorname{DevInd}_{i}$ is the development index score for individual $i$ 's current place of residence. Columns (2)-(4) report estimates of the same equation taking DevInd $_{i}$ to be the development index score for individual $i$ 's place of residence during the ages of 13-18, 7-12 and 0-6. Columns (5)-(8) repeat the exercises in columns (1)-(4) taking mother's years of schooling as parental education input. Standard errors are clustered at the province level. Standard errors in brackets ***

$\mathrm{p}<0.01, * * \mathrm{p}<0.05, * \mathrm{p}<0.1$. 
Table 9 - Sensitivity to Various Definitions of Area of Residence among Migrants

\begin{tabular}{|c|c|c|c|c|c|c|c|c|}
\hline & \multicolumn{4}{|c|}{ Father-daughter } & \multicolumn{4}{|c|}{ Mother-daughter } \\
\hline & Current res. & $13-18$ & $7-12$ & $0-6$ & Current res. & $13-18$ & $7-12$ & $0-6$ \\
\hline VARIABLES & (1) & (2) & (3) & (4) & (5) & (6) & (7) & (8) \\
\hline Devindex & $\begin{array}{l}-0.014 \\
{[0.130]}\end{array}$ & $\begin{array}{c}0.526^{* *} \\
{[0.206]}\end{array}$ & $\begin{array}{c}1.134^{* * *} \\
{[0.375]}\end{array}$ & $\begin{array}{c}1.367^{* * *} \\
{[0.283]}\end{array}$ & $\begin{array}{l}-0.073 \\
{[0.135]}\end{array}$ & $\begin{array}{c}0.510^{* *} \\
{[0.208]}\end{array}$ & $\begin{array}{c}1.085^{* * *} \\
{[0.377]}\end{array}$ & $\begin{array}{c}1.299 * * * \\
{[0.299]}\end{array}$ \\
\hline Parent's education & $\begin{array}{c}0.799 * * * \\
{[0.072]}\end{array}$ & $\begin{array}{c}0.742^{* * *} \\
{[0.055]}\end{array}$ & $\begin{array}{c}0.733^{* * *} \\
{[0.054]}\end{array}$ & $\begin{array}{c}0.721^{* * *} \\
{[0.053]}\end{array}$ & $\begin{array}{c}0.885 * * * \\
{[0.080]}\end{array}$ & $\begin{array}{c}0.863^{* * *} \\
{[0.057]}\end{array}$ & $\begin{array}{c}0.843^{* * *} \\
{[0.060]}\end{array}$ & $\begin{array}{c}0.831^{* * *} \\
{[0.058]}\end{array}$ \\
\hline Parent's education*devindex & $\begin{array}{l}-0.007 \\
{[0.026]}\end{array}$ & $\begin{array}{c}0.010 \\
{[0.028]}\end{array}$ & $\begin{array}{c}-0.070^{* *} \\
{[0.028]}\end{array}$ & $\begin{array}{c}-0.096 * * * \\
{[0.032]}\end{array}$ & $\begin{array}{c}0.004 \\
{[0.026]}\end{array}$ & $\begin{array}{c}-0.009 \\
{[0.039]}\end{array}$ & $\begin{array}{c}-0.096 * * * \\
{[0.036]}\end{array}$ & $\begin{array}{c}-0.126^{* * *} \\
{[0.032]}\end{array}$ \\
\hline Constant & $\begin{array}{c}3.167^{* * *} \\
{[0.482]}\end{array}$ & $\begin{array}{c}2.988^{* * *} \\
{[0.282]}\end{array}$ & $\begin{array}{c}3.361^{* * *} \\
{[0.280]}\end{array}$ & $\begin{array}{c}3.458^{* * *} \\
{[0.255]}\end{array}$ & $\begin{array}{c}4.137^{* * *} \\
{[0.484]}\end{array}$ & $\begin{array}{c}3.789 * * * \\
{[0.253]}\end{array}$ & $\begin{array}{c}4.162^{* * *} \\
{[0.254]}\end{array}$ & $\begin{array}{c}4.243^{* * *} \\
{[0.234]}\end{array}$ \\
\hline Observations & 710 & 708 & 710 & 710 & 707 & 705 & 707 & 707 \\
\hline R-squared & 0.346 & 0.377 & 0.387 & 0.396 & 0.329 & 0.359 & 0.368 & 0.378 \\
\hline
\end{tabular}

Notes: This table reports the same regressions reported in Table 8 for the migrant subsample where a person is defined as migrant if her current area of residence is different from her area of residence during the ages of 0-6 and 7-12. Standard errors are clustered at the province level. Standard errors in brackets $* * * \mathrm{p}<0.01,{ }^{* *} \mathrm{p}<0.05, *$ $\mathrm{p}<0.1$. 


\section{Table 10 - Correlates of Intergenerational Mobility in Education}

\begin{tabular}{|c|c|c|c|c|c|c|c|c|c|c|c|c|}
\hline \multirow[b]{2}{*}{$\underline{\text { VARIABLES }}$} & \multicolumn{2}{|c|}{ Father-all } & \multicolumn{2}{|c|}{ Father-son } & \multicolumn{2}{|c|}{ Father-daughter } & \multicolumn{2}{|c|}{ Mother-all } & \multicolumn{2}{|c|}{ Mother-son } & \multicolumn{2}{|c|}{ Mother-daughter } \\
\hline & Coefficient & R2 & Coefficient & R2 & Coefficient & R2 & Coefficient & R2 & Coefficient & R2 & Coefficient & R2 \\
\hline Devindex & $\begin{array}{l}-0.041^{* *} \\
{[0.015]}\end{array}$ & 0.360 & $\begin{array}{l}-0.032 \\
{[0.019]}\end{array}$ & 0.184 & $\begin{array}{l}-0.047^{* *} \\
{[0.021]}\end{array}$ & 0.286 & $\begin{array}{l}-0.062^{* * *} \\
{[0.013]}\end{array}$ & 0.651 & $\begin{array}{l}-0.036^{*} \\
{[0.018]}\end{array}$ & 0.227 & $\begin{array}{l}-0.076 * * * \\
{[0.019]}\end{array}$ & 0.545 \\
\hline \multicolumn{13}{|l|}{ School availability/access } \\
\hline Secondary school present age 7-12 & $\begin{array}{l}-0.412^{*} \\
{[0.221]}\end{array}$ & 0.211 & $\begin{array}{l}-0.121 \\
{[0.255]}\end{array}$ & 0.017 & $\begin{array}{l}-0.633^{* *} \\
{[0.282]}\end{array}$ & 0.279 & $\begin{array}{l}-0.653^{* * *} \\
{[0.210]}\end{array}$ & 0.426 & $\begin{array}{l}-0.270 \\
{[0.245]}\end{array}$ & 0.086 & $\begin{array}{l}-0.969 * * * \\
{[0.277]}\end{array}$ & 0.484 \\
\hline High school present age 7-12 & $\begin{array}{l}-0.306 \\
{[0.175]}\end{array}$ & 0.192 & $\begin{array}{l}-0.062 \\
{[0.201]}\end{array}$ & 0.007 & $\begin{array}{l}-0.519 * * \\
{[0.215]}\end{array}$ & 0.310 & $\begin{array}{l}-0.458^{* *} \\
{[0.175]}\end{array}$ & 0.344 & $\begin{array}{l}-0.186 \\
{[0.194]}\end{array}$ & 0.066 & $\begin{array}{l}-0.732^{* * *} \\
{[0.222]}\end{array}$ & 0.456 \\
\hline \multicolumn{13}{|l|}{ Gender culture } \\
\hline Fraction who choose spouse & $\begin{array}{l}-0.444^{*} \\
{[0.208]}\end{array}$ & 0.259 & $\begin{array}{l}-0.272 \\
{[0.254]}\end{array}$ & 0.081 & $\begin{array}{l}-0.559^{*} \\
{[0.266]}\end{array}$ & 0.253 & $\begin{array}{l}-0.635 * * * \\
{[0.205]}\end{array}$ & 0.425 & $\begin{array}{l}-0.229 \\
{[0.257]}\end{array}$ & 0.058 & $\begin{array}{l}-0.850^{* * *} \\
{[0.270]}\end{array}$ & 0.433 \\
\hline Highest years of sch. among relatives & $\begin{array}{l}-0.066 * * \\
{[0.023]}\end{array}$ & 0.376 & $\begin{array}{l}-0.024 \\
{[0.029]}\end{array}$ & 0.050 & $\begin{array}{l}-0.099 * * * \\
{[0.030]}\end{array}$ & 0.455 & $\begin{array}{l}-0.073^{* *} \\
{[0.026]}\end{array}$ & 0.379 & $\begin{array}{l}-0.031 \\
{[0.028]}\end{array}$ & 0.084 & $\begin{array}{l}-0.111^{* * *} \\
{[0.036]}\end{array}$ & 0.420 \\
\hline \multicolumn{13}{|l|}{ Educational inequality } \\
\hline Parental years of schooling Gini & $\begin{array}{l}0.603^{* *} \\
{[0.241]}\end{array}$ & 0.324 & $\begin{array}{l}0.551^{* *} \\
{[0.238]}\end{array}$ & 0.291 & $\begin{array}{l}0.539 \\
{[0.387]}\end{array}$ & 0.130 & $\begin{array}{l}0.923^{* * *} \\
{[0.204]}\end{array}$ & 0.611 & $\begin{array}{l}0.630^{* *} \\
{[0.222]}\end{array}$ & 0.382 & $\begin{array}{l}1.026^{* *} \\
{[0.390]}\end{array}$ & 0.348 \\
\hline
\end{tabular}

Notes: The first row of column entitled Father-all presents the results of a regression analysis in which we regress regional intergenerational regression coefficients estimated for Father-all pairs in Section 5.3 on the development index score of regions across 15 development regions specified in Section 5.3. The second row presents results from a similar regression where the independent variable is a measure of regional secondary school availability in a region. In the third, fourth, fifth, and sixth columns the independent variables are a measure of regional high school availability, a gender culture measure for each region, average years of schooling of relative with highest education for each region and a measure of regional educational inequality, respectively. The next five columns report the relationship between same independent variables and Father-son, Father-daughter, Mother-all, Motherson, and Mother-daughter mobility estimates, respectively. Number of observations in each regression is 15 . Standard errors in brackets $* * * \mathrm{p}<0.01,{ }^{* *} \mathrm{p}<0.05, * \mathrm{p}<0.1$. 


\section{Appendix - Constructing Development Regions}

In this Appendix, we explain how we group provinces in Turkey into 15 development regions. To do so, we first rank all the individuals in our sample according to the development index value of the province they resided between the ages of 7 and 12 . We assign each individual a development percentile rank and then divide the sample into 15 development regions based on their percentile ranks. Individuals who grow up in the same province and, hence, share the same development index value, are randomly assigned a different percentile rank according to this procedure. To prevent this randomness, for individuals who grew up in the same province, the percentile rank is replaced by the mean of the percentile ranks of all the individuals in that region. ${ }^{36}$ This construction ensures that individuals in a region grew up in provinces with similar socioeconomic development levels. We can compute a measure of the level of development for each region by taking an average of the development index values of individuals in a given region. Table A1 provides the resulting list of provinces within each development region while Table A2 presents several characteristics of the 15 development regions.

\footnotetext{
${ }^{36}$ This procedure is also adopted by Chetty et al. (2014).
} 


\section{Table A1 - List of Provinces in Each Development Region}

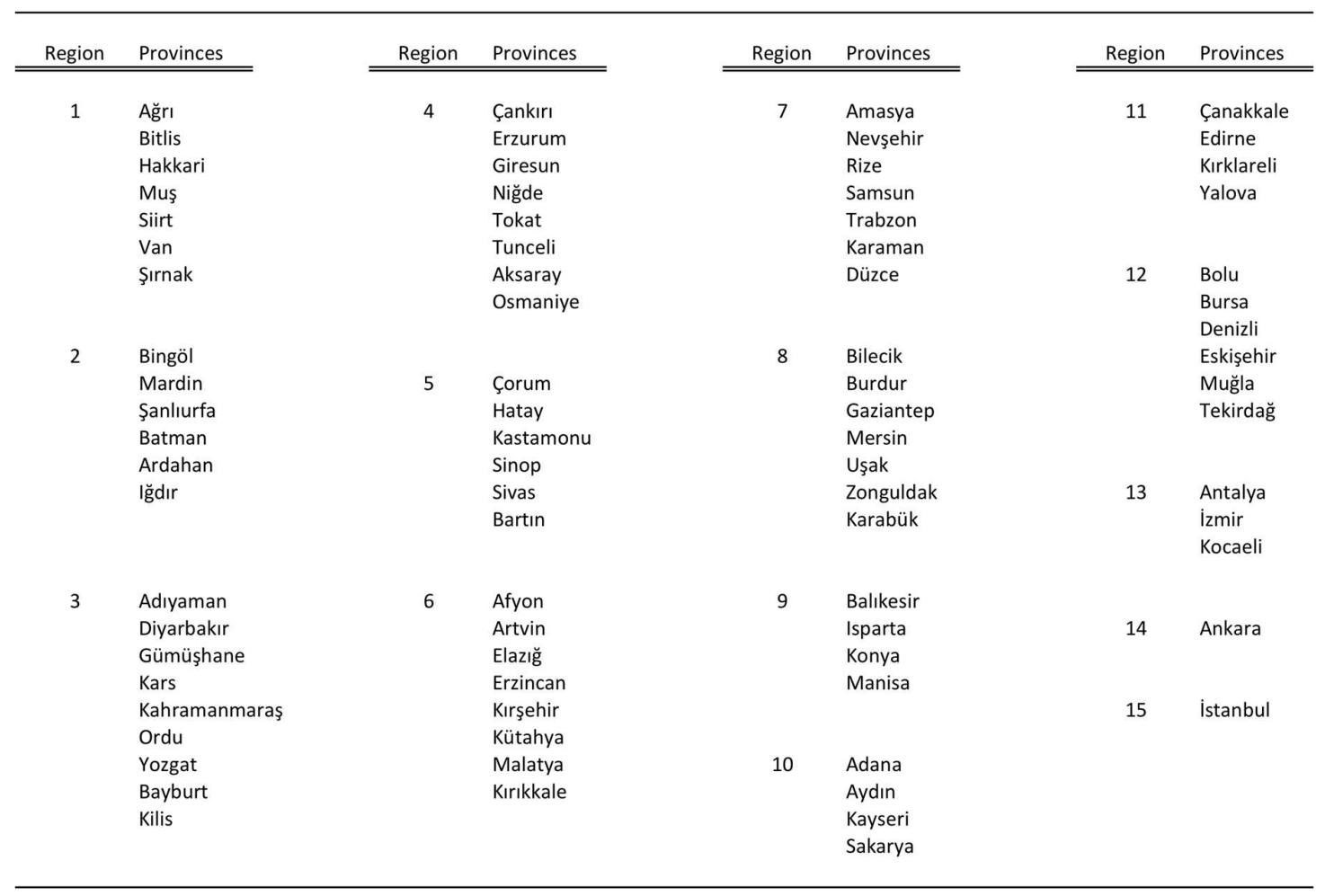

Notes: This table provides the list of provinces within each development region. See the discussion in this Appendix for the procedure used to construct 15 regions. By construction, each region consists roughly $1 / 15$ of all the individuals in the sample and the provinces within a region have similar socioeconomic development index values. 
Table A2 - Characteristics of Development Regions

\begin{tabular}{|c|c|c|c|c|c|c|c|c|c|c|c|}
\hline $\begin{array}{l}\text { Development } \\
\text { region }\end{array}$ & $\begin{array}{c}\text { Mean } \\
\text { development } \\
\text { index }\end{array}$ & $\begin{array}{l}\text { GDP per } \\
\text { capita (\$) }\end{array}$ & $\begin{array}{l}\text { Average years } \\
\text { of schooling }\end{array}$ & $\begin{array}{l}\text { Grade } 8 \\
\text { test score }\end{array}$ & $\begin{array}{c}\text { Student } \\
\text { teacher ratio }\end{array}$ & $\begin{array}{l}\text { Secondary } \\
\text { school present } \\
\text { age7_12 }\end{array}$ & $\begin{array}{l}\text { High school } \\
\text { present } \\
\text { age7_12 }\end{array}$ & $\begin{array}{l}\text { Fraction who } \\
\text { choose } \\
\text { spouse }\end{array}$ & $\begin{array}{l}\text { Parental } \\
\text { years of } \\
\text { sch. Gini }\end{array}$ & $\begin{array}{l}\text { Highest years } \\
\text { of sch. among } \\
\text { relatives }\end{array}$ & $N$ \\
\hline 1 & -1.47 & 802.53 & 3.78 & 213.76 & 31.35 & 0.62 & 0.52 & 0.54 & 0.70 & 9.17 & 245 \\
\hline 2 & -1.27 & 983.67 & 4.16 & 213.05 & 32.34 & 0.65 & 0.61 & 0.37 & 0.61 & 9.37 & 189 \\
\hline 3 & -0.78 & 1139.75 & 5.03 & 256.30 & 26.96 & 0.73 & 0.65 & 0.39 & 0.52 & 9.87 & 309 \\
\hline 4 & -0.36 & 1279.00 & 5.65 & 277.55 & 18.86 & 0.71 & 0.61 & 0.35 & 0.44 & 9.92 & 289 \\
\hline 5 & -0.19 & 1608.78 & 5.34 & 285.52 & 21.50 & 0.60 & 0.51 & 0.36 & 0.44 & 10.16 & 304 \\
\hline 6 & -0.06 & 1622.25 & 6.06 & 296.07 & 21.06 & 0.68 & 0.57 & 0.43 & 0.50 & 10.23 & 251 \\
\hline 7 & 0.17 & 1651.15 & 5.72 & 293.11 & 19.23 & 0.71 & 0.61 & 0.49 & 0.36 & 10.95 & 309 \\
\hline 8 & 0.33 & 2016.97 & 5.69 & 272.55 & 24.76 & 0.76 & 0.71 & 0.46 & 0.49 & 9.93 & 244 \\
\hline 9 & 0.50 & 1895.70 & 5.80 & 298.61 & 18.35 & 0.75 & 0.54 & 0.48 & 0.37 & 10.10 & 293 \\
\hline 10 & 0.57 & 2145.49 & 6.22 & 289.45 & 24.45 & 0.84 & 0.79 & 0.45 & 0.44 & 9.83 & 380 \\
\hline 11 & 0.61 & 2895.23 & 6.08 & 317.63 & 19.83 & 0.49 & 0.33 & 0.49 & 0.42 & 8.02 & 155 \\
\hline 12 & 1.15 & 2822.91 & 6.04 & 312.68 & 20.62 & 0.81 & 0.71 & 0.60 & 0.34 & 10.95 & 290 \\
\hline 13 & 1.83 & 3628.34 & 6.46 & 306.35 & 19.37 & 0.73 & 0.66 & 0.63 & 0.38 & 10.52 & 304 \\
\hline 14 & 2.84 & 2752.00 & 7.81 & 321.42 & 17.73 & 0.98 & 0.95 & 0.68 & 0.28 & 12.97 & 257 \\
\hline 15 & 4.52 & 3063.00 & 8.58 & 298.71 & 21.26 & 0.99 & 0.98 & 0.77 & 0.31 & 11.91 & 430 \\
\hline
\end{tabular}

Notes: This table presents several characteristics of the 15 development regions. Development index refers to the Socio-economic Development Index for 2011 published by the Turkish Ministry of Development where larger values of this index indicate more developed regions. GDP, years of schooling and teacher student ratio figures refer to year 2000, grade 8 test score values refer to year 2007. The information on GDP and teacher student ratio is based on province level statistics published by the Turkish Statistical Institute and national education statistics published by Ministry of Education, respectively. Grade 8 test scores are based on the nationwide SBS exam (Seviye Belirleme Sinavi) conducted in 2007 that assesses competency in mathematics, science, social sciences, and language fields. The remaining information in the table is based on the survey conducted for this paper. The last column reports the weighted number of observations in data used in this paper for each region. 
Table A3 - Intergenerational Correlations by Development Regions

\begin{tabular}{ccc}
\hline & & \\
Development region & Correlation coefficient & Standard error \\
\hline \hline & & \\
1 & 0.770 & 0.076 \\
2 & 0.607 & 0.083 \\
3 & 0.616 & 0.051 \\
4 & 0.636 & 0.047 \\
5 & 0.533 & 0.047 \\
6 & 0.644 & 0.049 \\
7 & 0.622 & 0.050 \\
8 & 0.554 & 0.050 \\
9 & 0.526 & 0.046 \\
10 & 0.632 & 0.044 \\
11 & 0.349 & 0.081 \\
12 & 0.470 & 0.045 \\
13 & 0.596 & 0.042 \\
14 & 0.416 & 0.047 \\
15 & 0.474 & 0.038 \\
& & \\
\hline
\end{tabular}

Notes: The results are based on separate estimations of equation (2) for each region. Following Hertz (2007), average years of schooling of parents is set as the parental education variable and the sample is restricted to individuals who are between the ages of 20 and 69. For each region correlation coefficient refers to that between (adjusted) average parental education and (adjusted) child's education. 